\title{
Du congrès de Munich aux événements universitaires de 1965 : une nouvelle opposition contre l'état de guerre continu
}

Del Congreso de Múnich a los acontecimientos universitarios de 1965: una nueva oposición contra el estado de guerra continuo

From the Munich Congress to the University Events of 1965: New Opposition to the state of Continuous War

\section{Vanina Filippi}

\section{(2) OpenEdition}

\section{Journals}

Édition électronique

URL : http://journals.openedition.org/bhce/2827

DOI : $10.4000 /$ bhce.2827

ISSN : 1968-3723

\section{Éditeur}

Presses Universitaires de Provence

\section{Édition imprimée}

Date de publication : 1 janvier 2020

ISSN : 0987-4135

\section{Référence électronique}

Vanina Filippi, « Du congrès de Munich aux événements universitaires de 1965 : une nouvelle opposition contre l'état de guerre continu », Bulletin d'Histoire Contemporaine de l'Espagne [En ligne], 54 I 2020, mis en ligne le 01 juillet 2020, consulté le 31 décembre 2020. URL : http:// journals.openedition.org/bhce/2827 ; DOI : https://doi.org/10.4000/bhce.2827

Ce document a été généré automatiquement le 31 décembre 2020.

Bulletin d'histoire contemporaine de l'Espagne 


\title{
Du congrès de Munich aux
} événements universitaires de 1965 : une nouvelle opposition contre l'état de guerre continu

\author{
Del Congreso de Múnich a los acontecimientos universitarios de 1965: una nueva \\ oposición contra el estado de guerra continuo \\ From the Munich Congress to the University Events of 1965: New Opposition to \\ the state of Continuous War
}

\section{Vanina Filippi}

1 Dans les années 60, la scène publique changea de physionomie avec la disparition progressive des querelles spécifiquement espagnoles sur l'essence de l'Espagne entre ceux que l'on nomma les « compréhensifs » et les « exclusifs ». Les débats des années 50 perdirent peu à peu de leur sens et changèrent de manière notable, poussés, parmi d'autres questions, par la force que prenaient les débats internationaux. L'intervention des intellectuels fut marquée par ce changement, puisqu'ils vivaient, dans un contexte de transformations sociales, dans une société différente de celle de l'après-guerre. La signature du Traité de Rome en 1957, notamment, s'ancra dans un processus ambitieux, qui allait bien au-delà de l'alliance économique, puisqu'il avait un caractère politique, dans la mesure où l'européanisme était identifié à la démocratie et où la couverture institutionnelle pouvait être utilisée dans un sens critique envers la dictature. C'est dans ce contexte qu'une nouvelle opposition put s'organiser et dont le symbole fut le Congrès de Munich de 1962, qui permit de renouer le dialogue et de réconcilier une nouvelle opposition contre la dictature, où exil et opposition surgie de l'intérieur s'entendraient sur un vocabulaire commun face à la terreur franquiste.

2 Cette nouvelle opposition en formation put se consolider au sein d'un nouvel exil, sanction imposée par Franco à la suite d'un Congrès considéré comme pure trahison. Ce nouvel exil apparut face à un exil qui était en train de disparaître, soit par extinction 
biologique, soit parce que certains exilés se posaient la question d'un possible retour ou parce qu'ils ne s'étaient pas mal adaptés à leur pays d'accueil. L'exil de 1939 avait perdu de son poids et, parmi les intellectuels critiques de «l'intérieur ", les exilés républicains étaient essentiellement un référent éthique, celui de ceux qui tentèrent de résister au franquisme, mais ils n'étaient pas un référent intellectuel ou politique opérationnel. Surtout pour les jeunes critiques de l'intérieur, les exilés utilisaient un langage politique désuet, duquel ils ne pouvaient apprendre, précisément parce que ces jeunes se sentaient attirés par des propositions ayant peu, voire aucun écho avec les années 30. Le retour d'Ortega eut des répercussions bien connues mais cela ne signifie pas qu'ait pu émerger une quelconque école capable de suivre ses propositions culturelles. Surgit, dans ce contexte de dictature attachée à cacher ce legs, un nouvel exil dans les années 60 avec des jeunes activistes qui fuirent la répression et devinrent les nouveaux exilés, mais qui étaient en totale syntonie politique et générationnelle avec la réalité critique de l'intérieur. Dionisio Ridruejo, ancien chef de la Propagande franquiste, devenu dissident, fit partie de ce nouvel exil à Paris, où il acquit avec d'autres intellectuels une stature d'opposant reconnu. Le Congrès de Munich et la sanction franquiste subséquente furent un atout qui permit à cet homme de s'exprimer à travers la presse de l'extérieur pour une Espagne démocratique. À l'intérieur comme à l'extérieur, les actions se multiplièrent et se coordonnèrent en vue de dépasser les conséquences de la Guerre civile et de préparer le futur de l'Espagne qui, désormais, devait se jouer en dehors du régime.

\section{Une opposition réconciliée à Munich}

Les courants qui, en Espagne, défendaient une association économique et politique plus étroite avec l'Europe, étaient en train d'acquérir une force irrésistible. Une série d'entités européanistes avaient en effet vu le jour : l'AECE (Association Espagnole de Coopération Européenne), la Ligue Espagnole de Coopération Européenne, l'Institut d'Études Européennes, etc., tous reliés au Conseil Fédéral Espagnol du Mouvement Européen. On convoqua à Munich un Congrès du Mouvement Européen. Maurice Faure, le président du Mouvement Européen, à l'occasion de son IVème Congrès Politique, avait invité pour la première fois plus de cent Espagnols de l'intérieur. Les membres de l'Association Espagnole de Coopération Européenne (AECE) avaient été invités à participer à un colloque spécial pour les Espagnols pour échanger leurs points de vue face aux problèmes posés par l'éventuelle intégration de l'Espagne en Europe. Les travaux devaient concerner l'étude de la «démocratisation des institutions européennes et des voies et moyens pour la création d'une communauté politique susceptible d'assurer un véritable progrès vers l'édification des États Unis de l'Europe » 1 .

4 La participation des délégués espagnols dépassa toutes les espérances. Parmi les 1500 Européens convoqués de toutes les nationalités, avaient été invités aussi certains Espagnols qui «viv(aient) en exil ${ }^{2}$. Participèrent des représentants des principales organisations de l'opposition modérée autant de l'intérieur que de l'extérieur - Le Parti Communiste et la CNT étaient donc absents- ainsi que des personnalités indépendantes. Parmi les 118 Espagnols présents, 80 venaient de l'intérieur, représentant toutes les tendances démocratiques -des monarchistes libéraux aux socialistes et les autres étaient des représentants des organisations en exil ${ }^{3}, 38$ de l'exil, représentant 
l'écrasante majorité des oppositions historiques. La délégation espagnole était la plus nombreuse des délégations nationales présentes au Congrès de Munich en juin 1962. Robert van Schendel, le secrétaire général du Mouvement Européen, avait invité en particulier les Espagnols deux jours avant le début officiel du Congrès pour "confronter leurs points de vue sur le problème de l'éventuelle intégration de l'Espagne en Europe et en déduire certaines lignes directrices» ${ }^{4}$. L'AECE dit avoir accepté l'invitation pour faire connaître l'opinion d'un secteur de l'intérieur de l'Espagne véritablement européaniste à ceux qui étaient en train de créer la nouvelle Europe. Car il leur semblerait « lamentable que seule fût écoutée la voix des Espagnols exilés ", tout en sachant qu'ils s'exposaient à une campagne de presse qui les accuserait de conclure un pacte avec les Espagnols de l'exil.

5 Les Espagnols de l'intérieur, du moins les membres de l'AECE, purent quitter l'Espagne sans encombre. À leur arrivée à Munich, le secrétaire général du Mouvement Européen invita à dîner sept Espagnols de l'intérieur et sept exilés, dans le but de se mettre d'accord sur la manière de procéder durant les délibérations mais l'AECE n'accepta l'invitation, souhaitant démontrer qu'ils n'allaient pas à Munich pour conclure un pacte avec les Espagnols exilés. José María Gil-Robles en personne affirma que les délibérations ne devaient se faire entre les Espagnols de l'intérieur et les exilés. Deux sections durent donc être constituées : la A) dans laquelle les Espagnols de l'intérieur se réunirent, présidés par Gil Robles en tant que Président de l'AECE, qui avait rédigé le projet de texte à soumettre au Congrès; et la section $\mathrm{B}$ ) dans laquelle les exilés délibérèrent sur le même texte. Gil Robles fut suivi et l'on délibéra dans les deux sections séparément mais en fin de journée, le secrétaire du Mouvement, constatant les différences entre les conclusions de l'un et de l'autre groupe, convoqua une réunion sous sa présidence pour tenter de s'entendre sur un texte commun. S'agit-il d'une version officielle édulcorée de l'AECE adressée au Caudillo? Quoi qu'il en soit, les représentants de l'opposition espagnole avaient organisé des réunions dans les salons du Grand Hôtel de Munich les 5 et 6 juin et cette rencontre fut, selon Arriba, le théâtre de la réconciliation entre certains anciens adversaires idéologiques et politiques. À cet égard, la poignée de main entre le démocrate-chrétien, ancien chef de la CEDA, GilRobles et le secrétaire général du PSOE en exil, Rodolfo LLopis, fut symbolique ${ }^{5}$ et elle fut particulièrement décriée dans la presse du Mouvement à travers l'article intitulé de manière éloquente "La traición y la estupidez, aliadas en sucio contubernio contra España » et sous-titré « Los restos de la más estéril politiquería -Gil Robles y LLopis- se dan la mano en Munich ${ }^{6}$. Le rédacteur de l'article ne comprenait guère comment deux personnages, "des avatars qui avaient conduit l'Espagne à la Guerre civile »; " séparés par les tranchées de ce combat provoqué par eux-mêmes ", pouvaient aujourd'hui oser une réconciliation théâtrale en public et la présenter aux Espagnols comme un symbole $\mathrm{du}$ futur démocratique de l'Espagne dont ils seraient les principaux protagonistes. De cette " réunion de conspirateurs", au "triste et ridicule résultat », Arriba ne retenait que cette poignée de main et les propos de Salvador de Madariaga qui, en les observant s'était exclamé que «ce jour resterait dans l'Histoire de l'Espagne car ce geste représentait le dépassement de la Guerre civile». La "manœuvre» que le journal nommait « réconciliation » n'était pourtant qu'une réunion privée et contrairement à ce que la presse du régime affirma, il n'y eut ni pacte ni accord politique, pour lequel aucun des assistants n'était mandaté. Mais après deux jours de discussions fécondes, les congressistes arrivèrent à un accord sur les prémisses politiques qui devaient présider et conditionner la possible entrée de l'Espagne dans les instances européennes. 
6 Dans le cadre du Congrès, dans des conférences et des colloques et dans toutes les autres manifestations publique et privée, l'opposition espagnole défendit la nécessité que l'Espagne intégrât l'Europe économique et l'Europe politique et elle eut l'occasion de débattre sur la situation interne du pays, parvenant à une série d'accords sur une possible et désirable évolution politique vers la démocratie. Ces échanges d'impression se conclurent par l'approbation à l'unanimité d'un projet de Résolution. Ce texte auquel on parvint fut défendu devant le Congrès par Salvador de Madariaga et José María GilRobles et fut ensuite soumis à l'approbation du millier de participants, qui l'accueillirent avec enthousiasme. Le texte ${ }^{7}$ établissait que l'intégration de tout pays en Europe, que ce fût sous la forme d'adhésion ou sous la forme d'association, exigeait dans chacun d'eux, des institutions démocratiques ce qui, dans le cas de l'Espagne, en accord avec la Convention Européenne des Droits de l'Homme et la Charte Sociale Européenne, signifiait l'établissement d'institutions représentatives et démocratiques qui garantissent que le Gouvernement était basé sur le consentement des citoyens; la garantie effective de tous les droits de la personne humaine, en particulier ceux de liberté individuelle et d'opinion et la suppression de la censure de gouvernement; la reconnaissance de la personnalité des différentes communautés naturelles ; l'exercice, sur des bases démocratiques, des libertés syndicales et la défense, pour les travailleurs, de leurs droits fondamentaux, dont celui de grève; la possibilité d'organiser des courants d'opinion et des partis politiques, ainsi que le respect des droits de l'opposition. Ce texte manifestait le profond espoir des signataires quant à l'évolution consécutive à l'application des cinq points mentionnés, ce qui rendrait possible l'intégration de l'Espagne dans l'Europe unie. Ce texte affirmait enfin prendre note de la ferme conviction exprimée par tous les délégués espagnols présents au Congrès que l'immense majorité du peuple espagnol désirait que cette évolution fût menée à son terme selon les règles de la prudence politique, aussi rapidement que le permettaient les circonstances politiques, avec sincérité de la part de tous, et leur engagement à renoncer à toute violence active ou passive, avant, pendant et après le processus d'évolution. Ce texte rendait possible que l'actuel régime espagnol, moyennant une intelligente et sincère évolution, pût intégrer l'Europe.

7 En marge du Congrès, Joaquín Satrústegui, en présence d'un groupe important d'Espagnols de l'intérieur et d'exilés qui l'écoutèrent avec respect, exposa longuement sa vision de l'avenir, -il employa la première personne du pluriel, "notre vision", démontrant qu'Espagnols de l'intérieur et exilés s'entendaient sur ce point-, fondée sur les affirmations suivantes : sa croyance que la Monarchie serait restaurée; l'évidence que les Monarchies étaient idéales pour l'intégration en Europe; la conviction qu'en Espagne la République n'avait pas d'avenir. Il s'agissait de parier sur une intégration dans une Europe essentiellement anti-communiste et qui croyait aux contrôles démocratiques ${ }^{8}$.

8 Dionisio Ridruejo, l'ancien chef de la propagande franquiste devenu dissident, à qui l'on avait retiré son passeport lors de sa détention et de son procès consécutivement aux événements universitaires de 1956, dut passer clandestinement la frontière francoespagnole pour pouvoir assister au Congrès de Munich. Bien que son rôle ne fût pas déterminant ${ }^{9}$, sa présence fut remarquée, comme en témoigne la mention de son nom dans Arriba ${ }^{10}$ :

« Dans cette curieuse association, qui ne cessera de surprendre le lecteur, il y avait des noms comme ceux de Prados Arrarte, Álvarez de Miranda, Fernández de Castro, Alfonso 
Prieto, Satrústegui et Ridruejo, d'un côté, et de l'autre, Fernando Varela, ministre du gouvernement républicain espagnol ; Irujo et Lundáburu, pour les séparatistes basques ; l'ineffable Salvador de Madariaga, Martínez Pareda, Javier Flores, etc. »

9 L'intellectuel y noua des amitiés solides avec Llopis ${ }^{11}$, qu'il ne connaissait peut-être pas avant le Congrès mais avec qui il initia une correspondance, quand Ridruejo formula sa demande à Llopis d'intégrer son parti à l'UFD (Unión de Fuerzas Democráticas), à laquelle ce dernier accéda. Il noua aussi une amitié sincère avec Julián Gorkin, qui consacra des années plus tard un article à cette rencontre hispano-européaniste pleine de sens, venant défendre le rôle de Ridruejo dans cette manifestation, lui qui fut l'un des artisans de ce dialogue tant désiré12 ${ }^{12}$ Gorkin soulignait chez Ridruejo un modèle de dignité et de décence, qui lui était apparu à l'occasion de leur rencontre durant la conférence historique de Munich, de leur collaboration ultérieure quotidienne durant près de deux ans et, lorsque Ridruejo rentra à Madrid, de leur relation continue jusqu'à sa mort. Durant la Guerre civile, les deux hommes se trouvaient à deux pôles opposés de la politique et pourtant ils se découvrirent une profonde affinité humaine et spirituelle, une sensibilité et un caractère communs. Sa rencontre avec un homme, qui aurait pu occuper d'importantes positions au sein du Pouvoir mais qui choisit volontairement le chemin inverse : celui des défis, des difficultés et des sacrifices, fut symbolique durant cette nouvelle étape déterminante pour le vivre-ensemble espagnol, sous couvert d'européanisme. Le dialogue souhaité -le premier dialogue hispanoeuropéaniste ouvert et sincère- et la conjonction des volontés et des efforts l'emportèrent sur les réserves et les préjugés traditionnels ${ }^{13}$. Les cinq points ${ }^{14}$ unanimement adoptés par la Conférence espagnole interprétaient de fait l'aspiration profonde à dépasser les conséquences de la Guerre civile, la volonté de promouvoir la réconciliation de l'Espagne avec elle-même et l'esprit fédéraliste européen mené aux régions et aux peuples péninsulaires. En effet, un peu plus tard et à l'occasion du Congrès Européen organisé à Cannes, une délégation portugaise s'ajouta aux délégations espagnoles. À la session de clôture, la résolution espagnole fut acclamée par un millier de délégués debout. Un moment émouvant car tous sentirent que l'Europe avait besoin de l'incorporation de cette position clef qu'était l'Espagne et que l'avenir de l'Espagne allait être déterminé de manière irréversible en fonction de l'Europe.

Ridruejo lui-même écrivit un article sur le Congrès de Munich, « Munich, un hecho ${ }^{15}$ » qui, répondant non seulement aux détracteurs d'Arriba, expliquait les intentions de cette réunion, à savoir permettre à l'Espagne de s'inscrire avec dignité dans la vie internationale, et constituait une attaque directe, et visible du monde entier, du régime de Franco, dont il dénonçait le pouvoir personnel et son anachronisme dans le contexte international. Deux puissantes raisons, à son dire, avaient mené plus d'une centaine d'Espagnols responsables à se donner rendez-vous dans la ville de Munich, pour se présenter devant le Mouvement Européen au sein d'une plateforme commune : l'une concernait les conditions internes de l'Espagne, l'autre son avenir international. Pour ce faire, beaucoup d'Espagnols avaient dû vaincre leurs préjugés, leurs rivalités et d'autres craintes de représailles. Ridruejo revenait sur le régime de Franco, affirmant que tout le monde savait que l'Espagne vivait depuis 1939, soumise à un régime de pouvoir personnel. Il se refusait à juger la Guerre civile, qui avait mené à cette situation car Ridruejo ne reniait rien de ces énergies politiques promues par cette guerre et les adhésions qu'elle avait suscitées, lui-même y ayant participé avec enthousiasme. Mais ces énergies avaient été réduites en cendres par une politique «de pure et simple 
conservation du pouvoir ». Il dénonçait les structures ankylosées qui neutralisaient les bénéfices de la croissance naturelle de l'économie espagnole et "laissaient sans efficacité morale la vie intellectuelle qui, contre vents et marées cherch(ait) son chemin sous l'inquisition autoritaire du système $»^{16}$. Quant aux institutions, elles étaient de pures émanations bureaucratisées de l'unique institution effective: l'institution personnelle incarnée par le dictateur. Exclue de toute participation dans le système, l'opinion publique gisait dans un état de passivité que le régime interprétait quotidiennement comme un assentiment, s'en tenant à la maxime «qui ne dit mot consent ", " comme si le silence de ceux qui étaient muselés pouvait être éloquent ». Il dénonçait les soutiens de la dictature, comme l'Église ou la haute bourgeoisie, appuyés sur leurs propres intérêts, qui ne pouvaient en aucun cas servir l'opinion publique. Dans de telles conditions, la dictature manquait de possibilités futures et son système de pouvoirs dépendait exclusivement de la vie du dictateur. Car si l'Espagne voulait affronter de manière ordonnée et pacifique la prévision de son futur, elle devait recomposer un système de forces réelles, représentatives des groupes et intérêts du pays. Et ce sont précisément les représentants de ces groupes et de ces idéologies qui, dépassant leur éloignement historique, s'étaient rencontrés à Munich. Leur objectif ne pouvait être que celui d'offrir à ce pays, vidé par l'exclusivité du pouvoir, un système de forces suffisant pour garantir la paix civile aux Espagnols par l'accord du «vivreensemble démocratique ». Or l'Espagne, regrettait Ridruejo, vivait marginalisée sur le plan international depuis 1945, date à laquelle s'était effondrée la prétention d'un ordre mondial soutenu militairement par les puissances de l'Axe et dans lequel le régime de Franco aspirait à trouver une place rayonnante. La persistance d'un régime, qui semblait déjà réactionnaire et anachronique à ses propres alliés fascistes, y compris Ridruejo, était maintenant une extravagance inadmissible au sein de l'ordre mondial défini par le résultat de la guerre. Si la dictature avait incarné les principes de patriotisme, elle aurait trouvé la manière d'adapter la politique espagnole aux nouvelles circonstances en offrant au monde un interlocuteur valable. Mais elle avait préféré identifier l'Espagne au pouvoir personnel de Franco et s'enfermer sous ses ordres dans une position tenace. Elle avait réussi à maintenir sa position grâce au poids de la guerre "moralement continue ", de la forte répression conséquente et à celui de la terreur que provoquait chez le peuple espagnol «le fantasme de son propre passé immédiat ». Mais cette alternative entre l'isolement et la reproduction de la tragédie n'avait pas de réalité : elle était le chef d'œuvre, éclairait Ridruejo, « de l'égoïsme d'un régime décidé à rester au Pouvoir ", alors même que la défaite des puissances de l'Axe imposait un changement de stratégie. Il y avait d'autres options, Ridruejo revint précisément sur la volonté de réforme à l'intérieur du régime qu'il nommait la réforme interne du système ; la restauration d'une monarchie conciliatrice ; la préparation d'un gouvernement constituant qui préparerait loyalement les forces d'une démocratie viable. Mais toutes ces solutions avaient été abandonnées au profit du « chemin des simulations formelles ", prenant la forme de la "démocratie organique ", qui n'avait rien de réel et en laquelle pas même ses propagandistes ne croyaient. D'ailleurs le monde, jugeait amèrement Ridruejo, n'avait pris nullement en considération ces "déguisements " et les occasions de s'intégrer avec dignité à la vie internationale échappèrent à l'Espagne: le Plan Marshall, la constitution des Nations Unies, la formalisation de l'alliance occidentale, le début du processus de l'intégration européenne, "furent pour l'Espagne des événements étrangers et inaccessibles». L'Espagne était ainsi reléguée à un second plan sur tous les projets de la vie 
internationale. Ridruejo ne pouvait supporter cette situation où l'Espagne devait choisir une fois de plus entre la marginalisation, l'accord honteux et insatisfaisant et la conservation de son pouvoir réactionnaire ou la réforme de son système.

11 Réunis autour de cette analyse, les congressistes de Munich avaient voulu offrir à l'Europe l'instrument valide de négociation avec l'« Espagne réelle » pour intégrer cette dernière au Marché Commun et à l'Europe politique dans des conditions de parité et de dignité que la dictature rendait une fois de plus impossibles. Ridruejo conclut son article sur la réaction du gouvernement de Franco face à la réunion de Munich, qui attaquait ses deux points faibles : son incapacité à prévenir le futur et son incapacité à donner à l'Espagne une représentation autorisée dans les négociations internationales. L'intellectuel dénonçait le modèle de calomnie et d'inversion des termes dont était coupable le régime de Franco dans ses accusations contre "nous" -ce "nous " ne faisant plus référence aux phalangistes dans lesquels il s'incluait il y a peu de temps encore mais à cette nouvelle opposition main dans la main avec l'exil- : « celle de nous nier toute virtualité représentative par rapport à l'opinion espagnole et celle de nous accuser de trahison à la Patrie ». Selon les versions officielles, n'hésitait guère à dévoiler Ridruejo, « nous serions les « méchants » du western sans fin en quoi consiste la propagande officielle du franquisme». Par cette diatribe lancée contre le régime, Ridruejo devenait sur le plan international son opposant public, ce qu'il jugeait être depuis de nombreuses années, comme il l'affirmerait au directeur de Combat:

Je n'ai jamais donné ni ne donnerai jamais ni au Gouvernement espagnol ni à ses ambassadeurs, aucune explication sur mon activité politique. Celle-ci est une activité de pleine et publique opposition depuis de nombreuses années, et si je retournais en Espagne, ce serait toujours pour la poursuivre ${ }^{17}$.

12 La réaction officielle du Gouvernement espagnol -qui avait tenté par tous les moyens de pression diplomatique d'empêcher que cette Résolution fût présentée-, face aux résultats de Munich et à l'écho international qu'ils eurent, ne se fit point attendre et elle fut démesurée. La traditionnelle campagne de presse se déchaîna, dénonçant les événements comme un complot des ennemis de l'Espagne, comme un «lamentable épisode anti-espagnol», "un putsch de ratés nostalgiques, un accord dans l'impuissance politique $\aleph^{18}$. Dans cette campagne, la presse phalangiste se montra particulièrement belligérante, qualifiant le Congrès de «trouble pacte de Munich ${ }^{19}$ » et alléguant que les Espagnols, qui s'y étaient réunis, avaient contribué à fermer à l'Espagne les portes de l'Europe ${ }^{20}$. Ils allaient "contre le régime espagnol », rompre l'unité politique espagnole, recréer les partis, permettre ou encourager le séparatisme. Ils étaient vus comme des ratés de la politique, représentant la Monarchie libérale, la CEDA, le socialisme, les démocrates de l'un et l'autre camp, les séparatistes, etc. Tous avaient eu leur occasion de pouvoir. Tous avaient "monopolisé ou participé » à des gouvernements. Et qu'avait apporté de bon, de stable et de constructif leur action politique, en quoi avait-elle amélioré la vie du peuple -interrogeait Pueblo ${ }^{21}-$ ? Dans certains de ces articles polémiques, il y avait de claires références à Ridruejo, toujours sur le ton du discrédit si ce n'est de l'insulte. Il était vu comme un traître, un intellectuel médiocre, devenu l'ami des communistes :

Des intellectuels inférieurs, des poètes aux (...) sonnets sans âme, des convertis, qui profitèrent du Pouvoir et qui l'adulèrent jusqu'à ce que ce dernier les rendît à leur condition de médiocrité, lorsqu'ils démontrèrent qu'ils étaient moins que des médiocres; des joueurs (...) de cartes truquées, qui veulent continuer de jouer leur 
partie contre le peuple espagnol, peu importe sous quel drapeau; compagnons de route des communistes, qui croient voyager à leur gréz 2 .

Le Gouvernement suspendit pendant deux ans l'article 14 du Fuero de los Españoles - qui précisait : « Les Espagnols ont le droit de fixer librement leur résidence sur le territoire national »- et imposa ainsi à quinze des participants au Congrès de Munich venant d'Espagne, l'obligation de résider sur les îles de El Hierro et Fuerteventura, des lieux où le dictateur Primo de Rivera avait déjà l'habitude d'interner ses opposants idéologiques. L'alternative à la décision du gouvernement était de rester en dehors du pays, c'est-àdire l'exil. Ridruejo et d'autres Espagnols, -l'avocat et dirigeant démocrate-chrétien Gil Robles, le professeur d'Économie, chef d'étude de la Banque Centrale, le professeur Prados Arrarte, etc.- qui avaient assisté au Congrès de Munich choisirent cette dernière solution pour continuer leur combat pour la démocratie. C'est ainsi que se constitua, face à la violence et à l'intolérance du régime, le nouvel exil.

\section{Le nouvel exil}

\section{La nécessité de l'exil pour poursuivre le travail intellectuel}

L'arrivée de Fraga au ministère de l'Information et du Tourisme avait suscité un certain espoir chez les intellectuels en Espagne mais ces derniers se rendirent compte que la situation s'assombrissait concernant la censure, à la Radio en particulier, comme le confia Rafael Flórez à Ridruejo en août 1962, avec l'apparition d'un certain nombre de règles depuis le $1^{\mathrm{er}}$ août :

Pour nous qui travaillons quotidiennement dans la presse, plusieurs possibilités se conjuguent qui laissent entrevoir pour cet automne-hiver une plus grande liberté d'expression. Mais, moi, je suis peu optimiste, car ce ceux sont les mêmes chiens avec des colliers différents qui sont aux affaires ${ }^{23}$.

Avant même le Congrès de Munich, une lettre que José Luis Abellán avait adressée à Ridruejo, alors qu'il venait de quitter l'Espagne pour Porto Rico, informe de la nécessité pour l'intellectuel de l'époque de s'exiler pour continuer sa " tâche " ${ }^{24}$. Ainsi cet exil ne s'imposait plus seulement à l'intellectuel de gauche mais aussi à l'intellectuel de droite, à l'intellectuel tout court, qui étouffait dans la culpabilité que le régime faisait peser sur ses épaules. Abellán, une fois arrivé sur les terres américaines, dit pouvoir enfin vivre, respirer, dire ce qu'il voulait. Cette silencieuse Inquisition de l'Espagne n'était plus. Lorsqu'il regardait en arrière, il dit éprouver la sensation de s'être libéré de quelque chose de dur, d'une culpabilité :

«Sans exagération dans toute la plénitude du vocable -je m'en rends compte maintenant- en Espagne l'intellectuel est un être coupable, la société jette sur lui une sensation étouffante de culpabilité ; je suppose que cela vaut seulement pour l'intellectuel de gauche; je crois que l'intellectuel de droite -réactionnaire, catholique, petit bourgeois- doit se sentir bien. Peut-être que je me trompe ; il est probable qu'en Espagne être un intellectuel tout court soit déjà une culpabilité ; peut-être que cela revient au même d'être de gauche ou de droite : le péché serait alors simplement l'intellectualité, l'intelligence : malédiction de l'homme ! »

17 Sa sensation actuelle en Amérique latine était celle du bien-être mais cela ne suffisait pas à Abellán, qui aspirait à des objectifs plus ambitieux, et qui essaierait donc de 
poursuivre un «travail intellectuel ", refusé en Espagne. L'exil à Paris fut à ce même titre une occasion de poursuivre cette tâche devenue impossible à l'intérieur.

\section{L'exil réconciliateur à Paris}

18 En juin 1962, un groupe de personnalités politiques et intellectuelles débarqua à Paris directement depuis Munich. Ridruejo et certains de ses amis et coreligionnaires, parmi lesquels Fernando Baeza, José Suárez Carreño et Pablo Martí Zaro, Vicente Ventura, Pepín Vidal (José Vidal Beneyto), Víctor Hurtado, en faisaient partie. Quelques jours plus tard, expulsés de l'Espagne par les autorités, arrivèrent aussi à Paris d'autres amis politiques de Ridruejo, qui avaient assisté à la réunion de Munich, dont Jesús Prados Arrarte et Enrique Ruiz García ${ }^{25}$. Eu égard à l'attitude répressive et au concert d'insultes déchaîné par le gouvernement de Franco, Ridruejo et son groupe décidèrent de rester à Paris durant un certain "temps raisonnable ", ce qui supposa presque deux ans d'exil. S'unit au groupe un exilé de 1939, qui jouissait d'une certaine notoriété, Enrique Gironella (Enrique Ardroer), ancien dirigeant du POUM (Parti Ouvrier d'Unification Marxiste), qui s'était modéré avec les années pour finir adepte d'un européanisme socialisant et, plus concrètement, serviteur d'une eurocratie conservatrice au rang de laquelle il occupa un poste d'une certaine importance ${ }^{26}$. Ce groupe formerait alors, avec Ridruejo en tant que tête visible et membre de plus grand poids, le Partido Social de Acción Democrática (PSAD).

19 Ainsi obligé de rester à Paris, tout comme d'autres délégués du Congrès de Munich, Ridruejo entama une collaboration fraternelle et étroite avec Gorkin, qui rappelaque l'intellectuel avait déjà collaboré à la revue sociologique et culturelle Cuadernos ${ }^{27}$, fondée en 1953, et qui fut à la fois une tribune libre et un pont pour le dialogue entre les intellectuels espagnols de l'exil et ceux de l'intérieur. Il lui suffit de citer certains des principaux collaborateurs: Luis Araquistáin, Américo Castro, José Ferrater Mora, Francisco García Lorca, Jorge Guillén, Salvador de Madariaga, Claudio Sánchez Albornoz, Ramón Sender ; mais aussi José Luis Aranguren, Camilo José Cela, José Luis Cano, Pedro Laín Entralgo, Julián Marías, Dionisio Ridruejo, etc. Une tribune d'analyse et de dialogue aussi pour les grandes figures intellectuelles et politiques latinoaméricaines et européennes. Pour les figures latino-américaines: les vénézueliens Rómulo Gallegos et Rómulo Betancourt, le colombien Eduardo Santos, le costaricain José Figueres, les péruviens Haya de la Torre et Luis Alberto Sánchez, les méxicains Alfonso Reyes, Jaime Torres Bodet et Octavio Paz; les argentins Victoria Ocampo, Jorge Luis Borges et Francisco Romero ; les cubains Jorge Mañach et Raúl Roa, etc. Et pour les européennes : Raymond Aron, Albert Camus, André Malraux, Alberto Moravia, Ignazio Silone, Bertrand Russell, et Aldous Huxley, Karl Jaspers et Arthur Koestler, etc.

En 1962, fut fondé à Paris le Centre d'Études et de Documentation, présidé par Madariaga, appuyé par le prestige de certains des grands noms espagnols cités plus haut, auxquels s'ajoutèrent les catalans Pablo Casals et Pedro Bosch Gimpera. Aussi, le dialogue ouvert à Munich exigeait une continuité et une tribune démocratique qui prit corps dans la revue Mañana. Gorkin en assurait la direction mais c'est Ridruejo qui se chargea principalement de la collaboration, d'abord à Paris puis à Madrid après son retour. Ils réussirent à réunir la collaboration des européanistes de l'exil, mais principalement ceux de l'intérieur, car c'est eux qui vivaient quotidiennement la réalité et les problèmes de l'Espagne. Ensemble ils réalisèrent des voyages au service de la cause 
espagnole. L'un à Strasbourg, invités par les assembléistes européens, principalement socialistes et démocrates-chrétiens ; ils assistèrent à un séminaire de jeunes Européens dans les environs de la ville; voyagèrent à Bruges avec Madariaga et assistèrent à l'inauguration du cours du Collège de l'Europe. Mais leur principal voyage fut New York et Washington, invités par les leaders syndicaux américains. Gorkin se remémora le banquet informatif à l'ONU, offert par un bon nombre d'ambassadeurs ibéroaméricains, les conférences publiques avec la présence de la presse dans les deux villes et, par l'intermédiaire du biographe de Manuel Azaña, le professeur Schlesinger, ami et conseiller du Président Kennedy. Et il rappela ces mots qu'ils entendirent de la bouche des Européens, des Ibéro-américains et des Nord-américains : «Si l'on poursuit l'accord dialogal adopté à Munich, notre position par rapport à l'Espagne changera en conséquence ».

Ridruejo, contraint à l'exil à Paris, devenait ainsi un symbole de l'opposition réconciliée avec l'exil à Munich, et il se fit connaître dans la presse parisienne. Le fait que 23 ans après la Guerre civile, des frères ennemis espagnols se retrouvassent ensemble en exil à Paris, était symbolique pour France-Soir ${ }^{28}$. Il s'agissait de

« Dionisio Ridruejo, ancien phalangiste et Prados Arrarte, ex-officier de l'armée républicaine, qui, lors de la guerre civile en 1936 se trouvaient dans des camps opposés ont été expulsés par Franco pour avoir assisté à la réunion des leaders de l'opposition, le 6 juin dernier à Munich. »

22 La rencontre en France de ces deux hommes, «l'un qui croyait à Franco ", l'autre qui " n'y croyait pas » ${ }^{29}$, ennemis pendant la Guerre civile, alliés aujourd'hui, avait quelque chose de particulièrement exemplaire. Franco leur avait donné à tous les deux le choix entre l'exil et l'internement aux Canaries, après le Congrès de Munich mais ils avaient préféré l'exil à Paris, "parce qu'ils ont choisi de combattre ensemble contre le Caudillo». Ces deux anciens ennemis avaient néanmoins des points communs. Ils avaient presque le même âge et pour les Espagnols de 50 ans, 1936 restait la date la plus importante de leur vie, parce qu'ils avaient 20 ans et parce que la Guerre civile venait d'éclater. Ridruejo y était présenté comme ancien membre de la Phalange et comme l'un des premiers à suivre le fondateur du Mouvement, José Antonio. Ses propos étaient rapportés: "J'étais jeune. J'avais été élève des collèges religieux. J'étais de la classe moyenne. J'avais des idées plein la tête. Je voulais que ça change. Je croyais qu'on allait faire la révolution nationale...». Mais le journaliste remarquait que Ridruejo ne cherchait pas à se justifier -«Il explique »- pensant encore que «José Antonio était un "senor (sic) » et que, lui aussi, s'il avait vécu, aurait depuis longtemps abandonné le franquisme ". Quant à Prados Arrarte, il « croyait à la révolution, mais à l'autre, celle de gauche, celle des paysans sans terre contre les «terratenientes" ... ». Tous les deux avaient " tourné en rond pendant trois ans comme des milliers d'autres, pleins de haine et de fureur dans cette Espagne où l'on tuait jusqu'à l'écœurement au nom du Christ ou au nom de la Révolution » " pour faire quelque chose, pour que ça change... ». Peut-être un jour, remarquait le journaliste, s'étaient-ils trouvés face à face sans le savoir, quand Ridruejo était au Pouvoir, ce qu'il ne cachait pas:«Moi, dit Ridruejo, en 1937 on commençait à me faire confiance. J'ai été nommé chef provincial à Valladolid. Puis ensuite membre du comité directeur de la Phalange et directeur général de la propagande... ». Au moment où Prados Arrarte dut finir par "s'enfuir en France pieds nus dans la boue de Perthus : «Il n'y avait rien d'autre qu'à faire qu'à essayer de ravaler sa rancœur lorsqu'on a été condamné pour le restant de sa vie à appartenir au camp 
des vaincus.». Mais aujourd'hui les deux hommes s'accordaient à dire que «Pour Franco, aujourd'hui comme en 1939, il n'y a que deux catégories d'Espagnols: les vainqueurs et les vaincus... ». L'Espagne de Franco était immobile depuis 1939, «figée dans les mêmes souvenirs, les mêmes terreurs et les mêmes absurdités " :

« Elle n'a pas bougé cette Espagne-là, car autrement elle l'aurait écrasé. C'est ça que nous voulons d'abord changer. Surmonter la guerre civile. Moi, les autres, Dionisio.

Nous ne voulons pas de la réconciliation des morts pour la patrie ou pour la révolution, mais la réconciliation des vivants. »

Ridruejo, par cette phrase, changeait officiellement d'espace. Il passait résolument à l'opposition extérieure, visant à dépasser les conséquences de la Guerre civile. Et pour que l'Espagne vécût, il fallait «chasser les mollusques, les mauvais souvenirs et ce régime anachronique ». Ils concluaient dans un "nous " fédérateur et annonciateur d'un combat fraternel et décidé contre le régime de Franco et la dichotomie vainqueurvaincu :

«En un seul siècle l'Espagne a connu trois guerres civiles. Alors ensemble nous disons : plus jamais. Et pour que cela soit, il faut aussi briser Franco et ce système absurde qui le protège. D'un côté les vainqueurs, de l'autre les vaincus. C'est pour ça que nous sommes ici... »

L'opposition ainsi réconcilie à Munich, symbolisée par l'accolade entre Gil Robles et Llopis et le duo Ridruejo-Arrarte, annonçait qu'elle lutterait main dans la main contre Franco par divers moyens, parmi eux la presse, en particulier extérieure. À travers cette presse, qui lui permit aussi de subsister, Ridruejo se faisait connaître dans ce nouvel espace en même temps qu'il poursuivait son combat. Il ne manqua pas de travail, en grande partie en raison de sa notoriété en tant qu'intellectuel dissident d'abord, puis en tant qu'opposant au régime de Franco, une image qu'il s'était forgée d'autant plus avec la publication par la maison d'édition Losada de Buenos Aires, en mars 1962, de son essai Escrito en España. De nombreux intellectuels lui tendirent la main à Paris mais aussi au Mexique ${ }^{30}$ ou encore au Vénézuela ${ }^{31}$, où l'on sollicitait sa collaboration au sein de journaux comme La República ou El Diario de Occidente de Maracaibo. Mais l'action des intellectuels dépassa le cadre strict de la presse, à travers diverses manifestations et protestations, pour se muer enfin en une action politique.

\section{L'action des intellectuels : réconcilier les deux Espagnes contre la Dictature.}

\section{Depuis la presse d'opposition extérieure. L'entente sur un vocabulaire commun}

Ridruejo, avant même les représailles du régime après le Congrès de Munich, avait accédé aux nombreuses demandes de collaboration au sein de la presse extérieure, d'abord pour donner une opinion sur la situation actuelle de l'Espagne, puis il se servit de cette dernière comme d'une véritable arme d'opposition. Dès 1956, Las Españas avait publié le rapport de Ridruejo à la Junte politique de la Phalange ${ }^{32}$. La même année, le premier numéro du Boletín de Información de la Unión de Intelectuales Españoles du Mexique lui consacrait un article qui louait son patriotisme et sa valeur civique ${ }^{33}$. En 1957, Diálogo de las Españas publiait le dialogue avec Luis Ortega Sierra de la revue 
cubaine Bohemia $^{34}$, suivi d'une réflexion sur les déclarations de Ridruejo ${ }^{35}$. Ces déclarations avaient eu la vertu de rendre nettement visible le point d'évolution politique auquel étaient arrivés la majorité des exilés au Mexique. Diálogo de las Españas comprenait le propos de Ridruejo lorsqu'il critiquait le régime. En exprimant sa déception et son dégoût, il mettait en lumière un état de conscience nationale dont la variété des nuances n'entravait pas la convergence vers un double dessein: sauver l'Espagne pour tous et rectifier radicalement les modes de "notre vie politique ». En dénonçant la fraude et la pauvreté franquistes, Ridruejo n'ajoutait rien à ce que l'exil savait déjà mais, ajoutait Arana, "l'importance de sa dénonciation n'(était) pas moindre » car elle témoignait de "notre » vérité et l'actualisait internationalement. Lorsque Ridruejo disait « Après tant d'années, beaucoup de ceux qui fûmes vainqueurs, nous nous sentîmes vaincus. Nous voulons l'être. ", la revue mexicaine s'accordait sur ce point car c'est l'Espagne tout entière qui avait été vaincue après la Guerre civile, et cela constituait la plus solide base pour asseoir le processus nécessaire de réintégration espagnole. Car ce qui importait était de s'entendre sur la répudiation commune de «nos » erreurs d'hier -la première personne du pluriel était employée pour signaler que vainqueurs et vaincus parlaient d'une seule voix- dans le but passionné de reconstruire l'Espagne sur les ciments de sa véritable tradition; "profondément humaine, maîtresse dans l'art de conjuguer les devoirs et les justices avec les libertés, pleine de respect pour la dignité de l'homme et pour les valeurs de l'esprit». La revue partageait donc l'opinion exprimée par Ridruejo, dans sa volonté de liquider l'esprit de la Guerre civile et de la dictature. Au même moment, le Bulletin de l'Union des Intellectuels au Mexique publiait sa lettre sur la mort de García Lorca ${ }^{36}$. En 1959, Ridruejo apparaissait dans des articles consacrés à l'opposition espagnole de l'intérieur ${ }^{37}$ et le Bulletin d'Information publiait un article de ce dernier sur l'orientation de la jeunesse espagnole ${ }^{38}$. Pour le numéro du mois de janvier 1961 de la revue The Atlantic Monthly ${ }^{39}$, Ridruejo avait écrit l'article «After Franco, What?", dans le cadre d'un supplément spécial sur l'Espagne aux côtés d'autres signatures prestigieuses dont celles de Julián Marías, Gregorio Marañón et José Luis Aranguren et d'un texte attribué à Antonio Machado. Mais l'article de Ridruejo fut amputé dans la mesure où avaient été éliminés ${ }^{40}$ certains des meilleurs paragraphes de son essai, en particulier celui où il faisait, selon l'éditeur, une "brillante comparaison» entre Primo de Rivera et Francisco Franco. Néanmoins, l'éditeur espérait que la revue anti-communiste Preuves pût consacrer un numéro spécial à l'Espagne en avril dans lequel serait inclus le texte original traduit en français. Cet article fut en outre l'occasion pour Preuves d'inviter Ridruejo et Gil Robles à participer à un débat public sur le thème «L'Espagne après Franco - L'Espagne et l'Europe $»^{41}$, prouvant que la voix de Ridruejo était importante à l'étranger. Anselmo Carretero y Jiménez avait fait appel à lui pour la préparation d'un numéro de Las Españas, grâce auquel ils souhaitaient renouer périodiquement la publication de la revue, lui demandant d'écrire un article qui exposerait le « moment actuel de l'Espagne et son immédiate évolution politique, juste après les événements de Munich $»^{42}$. L'équipe de la revue était alors persuadée qu'il était nécessaire de sortir d'affaire la politique espagnole et de la mener vers un large mouvement de reconstruction nationale, autour d'un travail commun à l'immense majorité du peuple espagnol.

26 Après le Congrès de Munich, Ridruejo, réduit au silence en Espagne, s'exprima fréquemment dans la presse francophone dans laquelle il put exposer ses idées et continuer d'attaquer le régime. Aussi, alors qu'il se trouvait à Paris, l'intellectuel se mit 
à la disposition de la presse extérieure, invitant le directeur de Combat et d'autres journalistes à directement le solliciter :

Me trouvant à Paris à la disposition de la presse, je vous saurais gré de ne pas accepter des versions sur mes attitudes venues de Madrid alors qu'il est si facile de les obtenir de moi-même. Il est déjà suffisant que les journalistes qui écrivent dans la presse de Madrid sur mes affaires fassent abstraction des sources authentiques. ${ }^{43}$

Ridruejo s'entretint avec Jacques Ferrier ${ }^{44}$ à qui il exposa les trois plus graves défauts du régime. Tout d'abord, Franco était lié aux groupes traditionnels, ce qui rendait impossible toute modification des structures sociales. En second lieu, le régime était établi sur la violence et la coercition : « Il a réduit l'Espagne à une sorte de nursery, où la circulation des idées n'existe pas, où la population n'est pas informée sur l'époque dans laquelle nous vivons ». Enfin, il s'agissait d'un régime provisoire, qui ne prévoyait rien pour l'avenir, qui abandonnait le pays à l'incertitude. Il était corrompu et il corrompait, en ce sens qu'il empêchait les citoyens d'avoir une responsabilité quelconque dans les affaires publiques. Cette corruption spirituelle «avilissait les Espagnols ».

L'intellectuel eut l'occasion de s'exprimer dans la rubrique "Les affaires étrangères » de L'Express dans l'article intitulé «Contre la guerre civile». La revue donnait la parole à ce «leader de l'opposition exilé par Franco", qui expliquait "comment les démocrates espagnols espèrent mettre fin à la dictature $»^{45}$. Ridruejo put revenir sur cette mesure d'exil qui pesait sur lui : "La mesure qui nous frappe (...) est une maladresse énorme de la part de Franco. Elle donne une publicité inespérée à la rencontre de Munich». Cette fois, affirmait-il, la vieille technique qui consiste à discréditer les adversaires du régime en les accusant de communisme ne convenait plus :

La presse officielle peut couvrir d'injures un homme comme Gil Robles, mais elle ne fera croire à aucun Espagnol que cet ancien leader des partis de droite sous la République s'est laissé séduire par l'idéologie communiste.

Cette accusation n'était pas moins absurde, selon Ridruejo, pour les autres « assignés à résidence ", qui étaient des démocrates-chrétiens comme Álvarez de Miranda ou des royalistes libéraux comme Satrústegui et Curiel. Quand les lecteurs espagnols constateraient que ces hommes étaient maintenant considérés comme dangereux, ils commenceraient à se demander si le danger ne venait pas plutôt du Gouvernement. Ridruejo expliquait également d'où était venue l'initiative de la rencontre de Munich face à un Marché commun qui était devenu une «sorte de mythe fascinant pour tous les Espagnols ». Ils y voyaient la fin de l'isolement, l'ouverture vers l'extérieur, le prétexte à un changement de régime. C'est cet élan, expliquait-il, qui avait été mis à profit pour organiser la réunion de Munich, dans le cadre du Congrès du Mouvement européen. Les 118 représentants de l'opposition avait adopté, rappela-t-il, une résolution déclarant que l'entrée de l'Espagne dans le Marché commun exigeait l'établissement d'institutions authentiquement représentatives et démocratiques, la garantie effective de tous les droits de la personne humaine, la liberté syndicale et le respect du droit à l'opposition. Il revint sur son parti «l'Action Démocratique ", qui n'était pas un parti de masse mais un mouvement d'intellectuels et de cadres socialistes qui s'efforçait surtout de jeter un pont, de jouer un rôle de liaison entre les différentes forces démocratiques de l'opposition. Enfin, peu importait que l'accord ne pût se faire du premier coup sur le problème des institutions futures de l'Espagne ou des réformes 
de structure à réaliser. L'essentiel était que tous les représentants de l'opposition eussent admis la nécessité d'un changement de régime et d'un retour à la démocratie.

L'opposition réunie, cette jeunesse, qui désirait penser le futur institutionnel et européen de l'Espagne, trouva dans la revue Ibérica un canal d'expression idoine. Victoria Kent, qui sollicitait Ridruejo depuis 1956, appela de ses vœux la collaboration de l'intellectuel et de « ses amis » à la revue du futur de l'Espagne, qui voulait donner la parole à la jeunesse qui "pense le futur européen de l'Espagne» ${ }^{46}$. Mais elle ne recevait pas de collaboration de l'intérieur et devait donc réduire le nombre de pages de la revue, dont la publication, chaque mois, était devenue une lutte ${ }^{47}$. En 1960, Ridruejo y était considéré comme une voix de l'opposition ${ }^{48}$. Les extraits les plus parlants de son entretien avec un journaliste du Figaro, dans lequel il dénonçait l'intolérance du régime, y furent publiés ${ }^{49}$. Son épouse venait d'être arrêtée alors qu'elle prenait part à une manifestation contre le coût de la vie. Ridruejo était alors décidé à aller jusqu'au bout de ses convictions. Les grèves, qui venaient d'éclater dans le pays, n'avaient pas seulement une valeur de propagande pour les usages extérieurs. Il était en revanche nécessaire de voir une prise de conscience du prolétariat espagnol, qui ne pouvait plus être contenu comme il y a dix ou quinze ans. C'était un fait politique nouveau et considérable. Aussi, Ridruejo relevait trois facteurs essentiels qui donnaient aux grèves tout leur sens : Tout d'abord, le régime n'avait pas su se rénover, il perdait en vitesse et il était caduque. Puis, les classes ouvrières se politisaient, elles prenaient conscience de leur force et de leur efficacité. Enfin, le Marché Commun exerçait une attraction irrésistible sur l'ensemble des éléments intéressés par ce dernier. Pour Ridruejo, les solutions pratiques résidaient sans doute au début dans une Monarchie constitutionnelle, qui s'appuierait sur les forces vives du pays. Au contraire, si la Monarchie acceptait de prendre sa place en faveur d'une dictature, il estimait qu'elle tomberait fatalement. Dans cet entretien, Ridruejo se qualifiait de libéral et, en tant que tel, il ne pouvait travailler que sur des hypothèses quant à l'avenir politique du pays, qui venait d'entrer dans une ère nouvelle depuis l'éclatement des dernières grèves.

31 C'est dans Ibérica que son article sur le Congrès de Munich, «Munich, un hecho $0^{50}$ » fut publié en juillet 1962, de même que les déclarations que Ridruejo fit à l'occasion de son passage par New-York ${ }^{51}$, après les événements de Munich. Il était ainsi présenté :

À l'occasion de son passage par New-York, Dionisio Ridruejo, fondateur du Parti Social d'Action Démocratique et l'un des organisateurs du Congrès du Mouvement Européen organisé à Munich au mois de juin, a fait à Ibérica ces déclarations. Dionisio Ridruejo est l'un des (intellectuels) sanctionnés par Franco comme conséquence de son intervention au dit Congrès.

Ridruejo s'était rendu à l'Université de Porto Rico, en compagnie de Gorkin dans le cadre des actions du Centre de Documentation et d'Études. Ainsi, en dépit du caractère officiellement privé de son voyage, il prit contact avec plusieurs associations d'exilés espagnols qui étaient intéressés par une information directe de l'Espagne et par un échange d'impressions avec certains amis américains de l'Espagne, qui désiraient connaître l'impact du Congrès organisé à Munich par l'opposition démocratique espagnole et s'informer sur les points de vue qu'avaient alors les démocrates espagnols en ce qui concerne l'avenir politique de leur pays, aussi inévitablement lié à la partie méridionale de ce continent. Ces "déclarations" sont le reflet des convictions de l'époque de Ridruejo pour qui la situation espagnole n'avait pas réellement changé depuis 1939. Il s'agissait encore d'un régime au pouvoir personnel concentré et 
irresponsable, socialement partagé par un syndicat d'intérêts : l'oligopole économique ; l'Église -qui avait gardé un certain monopole culturel- ; l'Armée qui restait unie par la fierté d'avoir vaincu la guerre et qui, d'une certaine manière, se faisait l'interprète des classes moyennes traditionnelles; la Phalange transformée en parti unique pourvoyeuse principale du personnel politico-administratif. Dans ces structures hiérarchiques, Ridruejo estimait que l'opinion politique n'y avait en aucun cas sa place ni même la manifestation des opinions au sein même des encadrements officiels. Toutes les formalisations institutionnelles du système -Cortès, municipalités, syndicats-, avaient manqué de vie authentique et avaient fonctionné, ajoutait-il, comme des artefacts bureaucratiques dépourvus de toute représentation et de toute capacité d'initiative. Pour Ridruejo, il n'y avait eu formellement aucun changement et la prétendue libéralisation du système n'était que simulation en ce qui concerne les structures politiques et la tolérance d'opinions libres. De surcroît, si le système se libéralisait, le principe du pouvoir personnel absolu courrait un risque et Ridruejo était convaincu que Franco ne courrait pas un tel risque pour son régime, dont il énuméra les exemples d'intolérance et de rigidité dans ses réactions répressives autant face aux grèves ouvrières qu'au Congrès de Munich. Pour ce qui est de la libéralisation annoncée de la presse, elle s'était limitée jusqu'alors à un changement de tactique, visible durant les grèves de l'été. Avant, ces faits avaient été mis sous silence, maintenant ils étaient publiés mais Ridruejo révélait les mensonges qu'on en disait. Sans doute, mesurait-il, était-ce un procédé plus habile. Néanmoins, des changements « de fait » avaient eu lieu. La pression de l'opinion internationale -que Franco devait ménager depuis qu'il avait des relations normales avec tout l'occident- était très effective dans la conduite du régime et avait limité sa liberté, en particulier du point de vue de la répression et des critères de censure. Cela rendait possible le développement d'une certaine opposition idéologique au sein du pays sans que disparussent cependant les répressions idéologiques et que cessassent de s'appliquer les méthodes de torture et les tribunaux d'exception. D'autre part, les appuis traditionnels du régime perdaient de leur consistance. Le parti unique s'était peu à peu dissout, il n'avait plus aucune importance. L'Église, ressentant la pression du mécontentement populaire, prenait soin de ne pas être associée à l'action du régime. Les groupes économiques dominants et la haute bourgeoisie en général comprenaient que Franco était un obstacle à la participation de l'Espagne dans des conditions normales au processus d'intégration européenne. Quant à l'Armée, qui désirait participer dignement à l'alliance occidentale, elle savait que Franco était le prix à payer pour l'intégration de l'Espagne dans l'OTAN. Tous ces facteurs, concluait Ridruejo, affaiblissaient le système et rendaient sa transformation inévitable au moment même où Franco vieillissait et n'inspirait plus confiance. Mais Ridruejo savait qu'il n'y aurait guère de changement en Espagne tant que l'on n'aurait préparé le système de forces capable de soutenir un régime nouveau. Ce système de forces ne pouvait être que démocratique car le régime, à part sur celle de l'Armée, ne pouvait plus compter sur des aides importantes dans l'opinion et parce que la pression mondiale l'exigeait ainsi. C'est convaincus de cela, assurait Ridruejo, que les groupes qui composaient l'opposition démocratique espagnole s'étaient réunis à Munich pour établir les premiers contacts entre les forces qui étaient en dehors de l'Espagne et celles qui se développaient à l'intérieur. Une rencontre satisfaisante, qui s'était traduite par une déclaration commune.

Les textes que Ridruejo écrivit eurent une répercussion notable à l'étranger. Parmi eux, «La guerra continuada », écrit après la mort de Julián Grimau, publié dans Ibérica ${ }^{52}$, et 
dont Le Monde avait déjà publié une version résumée ${ }^{53}$, eut une résonnance particulière, condamnant moralement l'assassinat de Grimau. Dans cet article, qui fut publié parallèlement à d'autres dans la presse étrangère, notamment dans Preuves ${ }^{54}$, -où Gorkin se prononçait contre la peine de mort infligée à Grimau, que ni son appartenance au comité central du parti communiste, ni les tentatives de réorganiser le parti clandestin à son retour en Espagne, ni les actes de solidarité avec les grévistes asturiens au printemps 1962, ne pouvaient justifier; et où il invitait les Espagnols à dépasser leurs clivages :

nous devons, nous Espagnols, fermer l'abîme qui nous sépare depuis la guerre civile, réprimer ou surmonter ses effets; nous devons créer un climat de compréhension, civile et civilisée, et nous devons enfin intégrer la nouvelle Espagne dans le concert des nations démocratiques

face à un Pouvoir qui «ne perd pas une seule occasion de réaffirmer, en gestes et en paroles, sa volonté de guerre civile. Elle lui a donné le pouvoir et elle le lui conserve ». Franco n'était-il donc pas lui-même «le symbole vivant de ce «délit permanent de rébellion militaire»? Ridruejo soutenait deux idées : D'une part, la condamnation de Grimau pour des délits présumés commis durant la guerre en connexion avec des activités illégales récentes, donnant lieu à un délit «continu », n'était possible qu'en raison du caractère du régime espagnol et parce que, pour ce dernier et surtout pour Franco, la guerre n'était pas terminée. D'autre part, la condamnation à mort de Grimau, qui était non seulement un acte cruel mais un acte absurde, était un acte de guerre, résultat d'une croissante faiblesse du régime, qui agissait ainsi pour réaffirmer son pouvoir. Car dans un contexte où la majeure partie de l'opposition était en train de réfléchir à une sortie démocratique sans revanchisme, sans demander des comptes aux vainqueurs de la guerre, le régime n'avait plus le mobile d'être le garant officiel face à une révolution communiste. Dans cet état de guerre continue, il s'agissait pour le régime de présenter l'opposition comme pur communisme et Grimau était le bouc émissaire idéal. D'ailleurs son cas n'était pas exceptionnel. Cette situation de guerre continue offrait une série ininterrompue de cas semblables. Ridruejo définissait le régime comme un système par lequel le pouvoir personnel imposait à l'automatisme simple de la justice militaire la répression de l'ennemi politique par un régime mis en péril dans une Espagne, qui était en train de se réconcilier idéologiquement et pour laquelle les situations de guerre continue ne seraient plus acceptables. De même, il était absurde de penser que cet assassinat arrêterait l'expansion du communisme qui, au contraire, trouvait ici un " nouveau et douloureux titre de prestige ", car Ridruejo était encore anti-communiste. Franco, par son acte de reconquête, qui définissait le style du pouvoir personnel, montrait que la piété humaine n'était rien face au Pouvoir et défiait une fois de plus la conscience morale universelle pour mettre fin aux dangers d'affaiblissement qui pesaient sur son système. Mais pour l'intellectuel, Franco avait mal calculé son geste, cette manière idéologique de lutter n'étant plus acceptable à l'époque pour les chrétiens, qui venaient de lire l'Encyclique de Jean XXIII, les hommes, qui pensaient que l'Espagne faisait partie de l'Europe, ou encore les militaires préoccupés par l'honneur du pays. Enfin, Ridruejo était persuadé que l'inhibition des collaborateurs du régime qui, jusqu'à présent avaient "encaissé silencieusement », ne durerait pas :

« Nous voulons penser (...) que l'on ne laissera pas se refermer le cercle de l'implication et de la peur, qui est l'essence même de l'état de guerre continu et du pouvoir franquiste.» 
35 d'Arriba ${ }^{55}$. Cependant, malgré cette condamnation au silence au sein du régime franquiste, Ridruejo et d'autres intellectuels de l'intérieur, maintenant exilés, trouvèrent dans la presse extérieure un canal d'expression pour lutter contre l'état de guerre continu en même temps qu'ils répondaient aux attaques du régime. Le Centre de Documentation et d'Études de Paris, et son bulletin devenu la revue Mañana, seraient d'autres outils de ce combat mené depuis l'exil.

Ce centre, créé en 1960, présidé par Madariaga avec l'aide de Gorkin, pouvait compter sur l'appui de certaines figures éminentes de l'exil politique et culturel, qui constituaient un «Conseil d'honneur» dans lequel se trouvaient Pere Bosch Gimpera, Pau Casals, Américo Castro, Josep Ferrater Mora, Francisco García Lorca, Jorge Guillén, Federico de Onís, Ángel del Río, Claudio Sánchez Albornoz et Ramón J. Sender ${ }^{56}$. Justino de Azcárate entretenait aussi une relation étroite avec le centre et l'aidait financièrement. Le financement de ce centre provenait en grande partie du Congrès pour la Liberté de la Culture, né durant la Guerre froide dans le but de constituer un front culturel dans le combat contre le communisme soviétique. Ce Congrès était financé et dirigé par la CIA américaine et pouvait servir objectivement à une stratégie globale du gouvernement des États-Unis dans la lutte contre le communisme, ce qui n'était pas contradictoire avec les positions politiques de Ridruejo ni avec celles de la majorité des collaborateurs du centre ${ }^{57}$. Il n'en demeure pas moins que ce centre offrit une véritable plateforme d'action pour l'opposition antifranquiste modérée. C'est précisément le Centre de Documentation et d'Études qui commanda à Ridruejo un rapport sur la situation espagnole de 1963, publié sous le titre España 1963. Examen de una situación, et dont les éléments essentiels furent incorporés par Ridruejo à la seconde édition de Escrito en España, que la maison d'édition argentine Losada publia en 1964. Aussi, Ridruejo et son groupe collaborèrent au Boletín informativo du Centre de Documentation et d'Études parisien, qui était publié depuis 1961 et dans lequel se trouvaient des rapports, des nouvelles et divers types de documentation sur la situation politique, sociale, économique et culturelle de l'Espagne. La publication du bulletin fut précédée par celle des Cuadernos del Congreso por la libertad de la Cultura, París entre 1959 et 1960, qui suivait déjà l'actualité politique et offrait une tribune de réflexion sur le régime, la démocratie, la future Europe et sur l'intellectuel lui-même et sa place dans la société espagnole. La plume de Ridruejo, analysait l'œuvre de Laín Entralgo ${ }^{58}$, côtoyait celle de Julián Marías, qui réfléchissait aux rencontres de Lourmarin ${ }^{59}$ ou encore celle d'Aranguren, qui développait sa pensée sur éthique et politique ${ }^{60}$. C'était un lieu particulièrement adapté à la réflexion sur le rôle de l'intellectuel, comme le fit Laín Entralgo dans le numéro 40 dans son article « El intelectual y la sociedad en que vive ${ }^{61} »$ ou encore Julián Marías, qui s'interrogeait sur la situation de l'intelligentsia en Espagne ${ }^{62}$. Ridruejo put y développer sa réflexion européaniste, notamment à travers l'article « La vida cultural española y la problemática europeísta »63, qu'il développerait dans l'élaboration du programme de son parti politique, le PSAD. Le numéro $19^{64}$ était entièrement consacré aux intellectuels et à la répression des grèves aux Asturies. L'article « Buscando claridad ${ }^{65}$ » était suivi de l'historique de la question de la première lettre des cent deux intellectuels à la réponse du ministre jusqu'à une lettre d'un prisonnier politique de Burgos. À l'occasion de l'assassinat de Julián Grimau, c'est un numéro spécial qui avait été publié et qui contenait l'article de Ridruejo, «La guerra continuada ${ }^{66} »$. 
L'intelligentsia publia sa réflexion sur l'intelligence dans ce bulletin informatif, qui trouva son prolongement dans la revue Mañana, toujours éditée par le Centre de Documentation et d'Études de Paris, qui permit une véritable collaboration entre l'exil et l'opposition intérieure, réduite au silence dans son pays. Dionisio Ridruejo co-dirigea la revue Mañana, Tribuna democrática española, éditée à Paris par le Centre de Documentation et d'Études, qui disposait de deux rédactions et qui avait deux directeurs délégués: le directeur officiel, devant assurer l'adéquation à la loi française, était Michel Collinet; Gorkin à Paris et Ridruejo à Madrid. Cette nouvelle revue mensuelle remplaçait le Boletín Informativo du Centre et Gorkin parvint à la financer grâce aux aides de l'AFL-CIO américain (l'American Federation of Labor-Congress of Industrial Organizations) et du parti social-démocrate allemand ${ }^{67}$. Néanmoins la revue rencontra dès le deuxième numéro des difficultés de financement ${ }^{68}$. $Y$ collaborèrent des hommes politiques et écrivains de l'exil et de l'intérieur, parmi lesquels Laín Entralgo, Aranguren, Tierno Galván, Tovar, Gil-Robles, Madariaga, le général Herrera, Marichal, Enrique Gironella, Gorkin, etc., démontrant une nouvelle fois que cette opposition réunissait anciens phalangistes, devenus opposants reconnus, et membres de l'exil, représentant l'opposition historique. Le premier numéro sortit en janvier 1965 et son éditorial intitulé "Cartel », qui constituait une déclaration de principes, fut sans doute rédigé par Ridruejo ${ }^{69}$. Cette revue était écrite " par et pour des Espagnols ", ne pouvant encore être éditée en Espagne. Elle aspirait à être l'organe de tous les Espagnols pourvus d'une conscience citoyenne, un exposant de l'opinion démocratique espagnole, et elle s'opposait au régime de monopole politique établi en Espagne. Les positions défendues étaient celles que Ridruejo défendait depuis déjà quelques années, à savoir une opposition ouverte à la dictature, un projet démocratique pour l'Espagne; un dialogue entre toutes les forces politiques sans autre exclusion que celle des fanatiques - Ils s'interdisaient toute expression de fanatisme idéologique ou de propagande violente, de même qu'ils excluaient l'ambiguïté et la simulation des opportunismes; la réconciliation et le refus de tout esprit de vengeance de la part des vaincus de la guerre. Cette opposition comprenait nécessairement deux fonctions : la critique de la situation et du gouvernement dont la substitution lui semblait obligatoire et la présentation à l'opinion publique d'une alternative. Cette opposition était ainsi définie :

"Notre opposition veut être, avant tout, un dialogue sérieux et constructif avec la société espagnole sur les intérêts et les aspirations de laquelle se fonde notre attitude. Le dialogue polémique entre Opposition et Régime n'est et ne sera pas celui de deux partis mais celui d'une minorité qui aspire à la représentativité des divers secteurs sociaux et une oligarchie qui séquestre violemment, sans aucun principe de représentation, l'Administration du pays. "

38 La revue rejetait l'arbitraire, la violence et l'injustice car ses créateurs et rédacteurs affirmaient la légalité, la raison et l'équité. Ils affirmaient la "Démocratie » car ils avaient fait l'expérience des maux et des limites de la « Dictature ». Cet éditorial était un plaidoyer contre la Dictature à laquelle ils s'opposaient car elle était née de la violence et car elle maintenait sa position dans l'arbitraire et la corruption. Elle n'était pas capable de traduire à un ordre légal stable les aspirations de paix de la société espagnole, ne faisant que feindre cette paix. Elle perpétuait un système social rigide au préjudice des secteurs les plus nombreux. Elle avilissait et désarmait la société espagnole en lui niant l'information nécessaire et la participation suffisante dans les affaires publiques. Son régime hiérarchique de favoritisme empêchait tout principe de concurrence loyale et imposait sur tous les plans de la vie nationale une sélection des 
cadres sans examen ni concours. Cette dictature poursuivait l'intelligence et conditionnait la vérité à ses fins particulières. Elle marginalisait l'Espagne du processus général de l'Occident et imposait des conditions d'infériorité dans tous les domaines des relations internationales. Enfin, elle ne représentait pas le peuple espagnol et elle ne comptait sur son jugement pour aucune décision. À la Dictature devait se substituer la Démocratie car elle

« suppose l'information de la gestion publique et les contrôles pour le Pouvoir. Garantie ferme des droits et des devoirs personnels. Négociation publique et rationnelle des conflits et oppositions réelles d'une société effectivement pluraliste. Participation explicite dans les affaires publiques de la société organisée en fonction de ses intérêts et aspirations. Liquidation de l'arbitraire. Correction des abus. Indépendance de la justice. Libération de la culture -ce que Ridruejo défendait depuis de nombreuses années-. Réforme de l'ordre économique injuste. Garantie de la dignité humaine. Sécurité dans la coopération libre. Progrès social homogène. Souveraineté effective de la nation. »

39 La Démocratie, affirmaient-ils, n'était pas "pour nous (...) une panacée " mais un régime qui avait fait ses preuves dans le plus grand nombre de pays avec des résultats maximaux de moralité, prospérité et cohésion sociale non forcée. L'intention de la revue était de dépasser les conséquences de la Guerre civile, qui avait été à l'origine d'une brutale division entre vainqueurs et vaincus, entre une Espagne soumise au totalitarisme fasciste et une Espagne exilée, avec des séquelles de rancœur et de haine ${ }^{70}$. Une division caractérisée ainsi par Madariaga : entre "ceux qui perdirent la terre pour sauver la liberté et ceux qui perdirent la liberté pour sauver la terre ». Finalement l'Espagne tout entière était vaincue. Il s'agissait maintenant de « la sauver, la réconcilier avec elle-même et d'intégrer de nouveau la liberté et la terre ». Une mission urgente et civile, qui incombait à tous les Espagnols qui « ressentent et aiment véritablement l'Espagne ». Les Espagne devaient cesser d'être pour que l'Espagne fût. Il fallait en finir avec la dénomination "Espagnols de l'intérieur " et «Espagnols de l'extérieur», au profit d'une dénomination supérieure et unique : « ceux qui souhaitent établir un nouveau vivre-ensemble civil dans les limites d'une Espagne démocratique et pluraliste et ceux qui souhaitent perpétuer l'état actuel des choses». Car ceux de l'intérieur n'étaient pas tous des « conservateurs ».

Dans cette revue, éditée jusqu'en octobre 1966, Ridruejo défendit en particulier la liberté intellectuelle, une plus grande variété d'opinions et une meilleure fluidité de l'information ${ }^{71}$. Il fut aussi l'auteur, en plus de ses articles signés, de plus de la moitié des articles et commentaires qui parurent sans mention d'auteur ${ }^{72}$. Il tenta d'éveiller les consciences citoyennes et s'éleva contre une passivité généralisée ${ }^{73}$. Il fallait penser à un nouveau consensus qui pût servir de base à la coexistence civile et ce dernier ne pouvait s'obtenir que sous la forme d'un authentique pacte social, à savoir un accord démocratique des divers secteurs du pays. Et cela était impensable tant que la passivité confiante se substituerait à la conscience citoyenne responsable et active.

41 Les articles de Ridruejo suivaient généralement l'actualité politique espagnole car il s'agissait aussi de mieux informer, de combler les lacunes de la presse officielle. Il y publia des lettres ouvertes, en particulier dans un contexte de tension au sein des universités, en février 1965, comme ce fut le cas à l'Archevêque de Madrid ${ }^{74}$,-sachant que l'Église n'était plus le soutien qu'elle fut pour le régime- auquel il exprima ses 
préoccupations à la lecture de la note de l'Association des «Padres de Familia » dans $A B C$ :

« Je crois que ces hommes (...) manquent démesurément à la vérité, à la justice et à la charité. À la vérité car ils méprisent les faits réels, connus de tous, pour construire une sombre histoire dans laquelle on calomnie le sens politique de la manifestation étudiante et le sens de l'intervention des professeurs, alors que l'on ignore ou que l'on absout l'immense responsabilité du Gouvernement... »

Ridruejo dénonçait de même l'attitude du Gouvernement qui, après avoir maintenu durant vingt-cinq ans l'Université politisée à travers le SEU, qui était l'une des sections de FET y de las JONS, accélérait maintenant sa politisation dans un sens inverse avec les résistances opposées aux revendications justes et avec la brutalité répressive menée à dessein contre l'Université "pour effrayer les timorés». Les "Padres de Familia", poursuivait Ridruejo, contrevenaient à la justice car ils introduisaient des jugements de valeur et des procès d'intention pour altérer l'ordre des responsabilités. Ils contrevenaient à la charité en demandant des peines et des châtiments contre les personnes calomniées. L'intellectuel en appelait à la conscience de l'Église qui, peu à peu était en train de reconquérir son crédit social grâce à l'action de nombreux prêtres intrépides guidés par la lumière miséricordieuse de Jean XXIII et qui ne pouvait donc s'exposer à voir son prestige actuel diminué par l'approbation en son sein d'un document aussi «ignoble». Enfin, Ridruejo souhaitait pour l'Église qu'elle fût un arbitre et un témoin d'un combat dans lequel «-je pense- son esprit milite -comme toujours- contre ceux qui oppriment et frappent-, bien que la chair, car elle est faible, ne soit pas toujours capable de suivre l'esprit ». Ridruejo, dans une lettre au directeur d'ABC, s'élevait en particulier contre cette rédaction, qui optait une fois de plus pour l'absence de raison et la force contre l'Espagne libre, et qui attisait la haine dans une véritable chasse aux sorcières. Il espérait que des voix ne manquassent pour empêcher de croire ceux qui le croient qu' $A B C$ représentait des classes et des causes qui, « pour le bien de la paix future, je n'aimerais pas voir aujourd'hui discréditées». Ridruejo demanda à ce que son écrit fût publié dans $A B C$, en vain. Mais Mañana se chargea de le publier.

La revue Mañana avait d'autres projets. Sa volonté, entre autres, était de tenter de faire entendre la voix des prisons espagnoles, pour refléter la vie dans ces dernières des détenus « politiques-sociaux ». Elle souhaitait également savoir ce qu'il se passait parmi les nouvelles générations uniformément mutiques. Il s'agissait de compléter l'information et les commentaires, les thèmes vifs et directs sur la réalité du pays et son évolution. Mais la vie de la revue fut de courte durée, sa fin étant le résultat de deux faits quasiment simultanés : l'apparition de revues qui, malgré de nombreuses limites, commençaient à remplir un rôle similaire à celui de Mañana, comme Triunfo et Cuadernos para el Diálogo, et le scandale après que fut rendue publique l'enquête selon laquelle la CIA était derrière le Congrès pour la Liberté et la Culture. Ce dernier ne fonctionna plus et le Centre d'Études et de Documentation cessa de recevoir des financements. Gorkin et Farreras cessèrent de toucher leur salaire, la revue ne fut plus publiée et le centre ferma ses portes ${ }^{75}$.

Parallèlement à la presse extérieure, se développait en effet une presse intérieure espagnole. L'action conjointe des intellectuels put s'exprimer à travers la revue Cuadernos para el Diálogo, qui n'était pourtant pas née pour être de l'opposition, envisageant, crut-on instant, un dialogue avec le Pouvoir, mais qui finit par traiter des 
mêmes thèmes que les revues de l'extérieur, tentant de parvenir au dialogue entre le vainqueur et le vaincu. Face à un dialogue impossible, il fallait envisager d'autres interlocuteurs.

\section{Cuadernos para el Diálogo : Le dialogue face à l'état}

\section{de guerre continu}

En octobre 1963, était publié le premier numéro de Cuadernos para el Diálogo qui annonçait, comme étant sa raison d'être, celle de favoriser le dialogue entre les hommes de tendances et attitudes les plus diverses sur les thèmes d'actualité qui passionnaient les Espagnols et le vivre-ensemble entre tous les Espagnols. Aux dires de Ruiz-Giménez, la revue n'eut pas un fondateur mais elle fut plutôt le fruit d'un état de conscience collective d'un groupe d'hommes qui ressentaient un mal-être intérieur et qui, du plus profond de leur esprit désiraient contribuer à « ouvrir des horizons». Cet état d'esprit se forma dans le climat des années 19621963 au moment où trois stimuli opérèrent sur les créateurs de la revue: la profonde rénovation chrétienne liée au Concile Vatican II et à la personne et l'enseignement de Jean XXIII ; une urgence d'ouverture sociale, intellectuelle, culturelle, qui préoccupa les cinq ou six personnes qui se rassemblèrent aux premiers instants, puis plus tard aux dix, et créer la possibilité qu'il y eût un authentique échange d'idées; enfin, un certain espoir de changement politique. L'espoir fut néanmoins frustré, jugea sept ans plus tard RuizGiméne $^{76}$. La revue naissait en effet comme une entreprise pratiquement impossible, reconnaissait Ridruejo ${ }^{77}$, dans sa volonté de faire dialoguer rationnellement tous les Espagnols de toutes les conditions. Cette revue voulait en effet initier le dialogue avec le Pouvoir mais, comme le démontra Aranguren dans le même article, cela était absolument impossible. Néanmoins, il y avait une mince possibilité et c'est celle qu'a exercée la revue précisément à travers les éditoriaux dont on a fait l'éloge, celle du dialogue, qui consistait en une dénonciation de ce qu'officiellement l'on voulait présenter comme étant un État de droit. D’ailleurs Ruiz- Giménez précisa qu'en réalité la revue n'était jamais née comme un instrument de dialogue avec le Pouvoir, c'est-àdire avec les institutions en place. Les fondateurs de la revue avaient déjà pleine conscience qu'il y avait trop de publications en Espagne qui se consacraient, si non au dialogue proprement dit avec le Pouvoir, à l'éloge du dit Pouvoir. Ainsi, la revue naissait considérant la société espagnole, la réalité espagnole et les possibilités d'influer d'une certaine manière sur un changement socio-économique et politique. Le dialogue catholico-marxiste avait ses limites mais Cuadernos permit d'envisager ce dialogue, comme un remède d'urgence entre le vainqueur catholique et l'ouvrier vaincu. Laín considéra que la revue avait joué un rôle dynamisant de la vie espagnole ce qui, selon lui, était un véritable exploit durant ces dix dernières années et ce mot "dialogue ", ajoutait Ridruejo, était une excellente conjuration face à cet esprit de persistance dans l'état de guerre. Pour Gregorio Peces-Barba, l'histoire de Cuadernos était celle de l'évolution des catholiques qui ont fait la revue, et il considérait que tous les catholiques présents lorsque fut publiée pour la première fois Cuadernos, étaient démocrate-chrétiens et qu'aujourd'hui existait un pluralisme, qui annulait la possibilité que les catholiques fussent à nouveau l'instrument utilisé par les secteurs réactionnaires pour une guerre fratricide. Pablo Castellano allait plus loin, affirmant que Cuadernos n'était pas une simple publication mais plutôt le reflet d'équipes de 
travail. Cette revue, à l'origine démocrate-chrétienne, sut s'ouvrir et convaincre les "juniors", dont faisait partie Pablo Castellano. Elle n'était pas une revue de l'opposition à proprement parler, elle avait ses défauts mais elle avait, selon les mots de Pablo Castellano, créé une conscience formative et assumé divers rôles, comme le rajoutait Félix Santos : "désintoxiquer, démythifier, informer, former, dialoguer à divers niveaux, être le chemin de l'expression de pluralismes idéologiques et politiques, etc. ${ }^{78}{ }^{\prime}$.

C'est ce qui la rendait si particulière dans le panorama de la presse espagnole. Aussi, elle remplissait son devoir informatif pour pallier les insuffisances des journaux et des hebdomadaires face à divers événements ou pour tenter de démystifier des versions déformées sur des faits aux dimensions politiques claires. Elle ne se disait donc pas porte-parole de l'opposition espagnole ni d'une seule de ses tendances mais elle avait conscience qu'elle devait agir en fonction de la transformation de la réalité en luttant pour maintenir l'espoir de ceux qui croyaient encore en la possibilité d'une transformation radicale de l'Espagne sur le plan culturel, socio-économique, religieux et politique.

La signature de Dionisio Ridruejo ne fut guère visible dans les années 60 dans Cuadernos para el Diálogo en raison de son éloignement, et de son interdiction d'écrire dans la presse espagnole, mais l'on ne peut douter de son soutien à la revue d'autant que cette dernière sollicita sa collaboration. Pedro Altares, secrétaire de rédaction, souhaitait publier ses poésies qui, selon lui, était injustement peu suffisamment connues ${ }^{79}$. On trouve certains articles de Ridruejo, dont un en 1966 dans lequel, toujours dans un souci d'information, il se proposait de réfuter les affirmations de Rodrigo Royo publiées dans S. P. le 17 avril $1966^{80}$.

Ridruejo ne fut guère fataliste face au silence imposé en Espagne et, outre les multiples articles publiés dans la presse extérieure et même intérieure, ses amis intellectuels et lui-même, constituant ce nouvel exil désireux d'en finir avec l'état de guerre continu, et de réconcilier les deux Espagne, multiplièrent les conférences, relayées par la presse de l'extérieur, de même qu'ils se mobilisèrent contre la répression exercée par le régime, notamment durant les événements ouvriers et universitaires, au prix, finalement, de leur propre liberté. Car les lettres ouvertes et autres protestations ou manifestes publiés dans la presse montrent combien l'action des intellectuels dépassait en réalité largement le cadre journalistique pour atteindre d'autres espaces, la rue en particulier.

\section{Conférences, manifestes et protestations}

Durant son voyage en Amérique, Ridruejo prononça des conférences dont une à l'Athénée Portoricain. Le périodique en exil España Libre rendit compte de cette conférence, à laquelle assistèrent une cinquantaine de personnes, la majorité d'entre eux antifranquistes ${ }^{81}$. Ridruejo y exposa le processus espagnol depuis la République, dans sa seconde étape, jusqu'au soulèvement de Franco, Mola et Sanjurjo et, comment, dès lors l'Espagne serait coupée en deux : les vainqueurs et les vaincus sans qu'il y eût la moindre tentative de la part de Franco et de son régime d'harmoniser ces deux moitiés. Face à des antifranquistes, Ridruejo brossait un portrait fidèle du phalangisme, qui avait fini par devenir une organisation bureaucratique. Il expliqua comment il abandonna le phalangisme en voyant qu'il devenait "quelque chose d'inerte » et insistait sur l'aspect totalitaire du régime dû à une personne qui ne semblait guère 
préoccupée par sa succession. Ridruejo, quant à lui, affirmait avoir confiance en la jeunesse, qui se réveillait vers un européanisme et se retrouvait étouffée au sein du régime franquiste. Selon España Libre, il disait croire que le régime évoluerait, qu'il le voulût ou non, vers des formes plus démocratiques car il se retrouverait sinon face à l'explosion révolutionnaire, insinuant qu'elle pût donner lieu à un castrisme espagnol, qui supposerait la ruine totale pour l'Espagne. Le correspondant de la revue décelait chez Ridruejo la sincérité et le souci pour les vicissitudes de l'Espagne franquiste, « qui est l'Espagne dans laquelle il a vécu ». Malgré l'intervention d'un prêtre, qui l'accusa de mensonge affirmant que les rouges avaient tué son père, sa conférence fut chaleureusement applaudie.

Alors que la voix de Ridruejo avait désormais son importance dans l'Espagne de l'exil, parallèlement, l'action des intellectuels, même restés à l'intérieur de l'Espagne, s'intensifia dans un contexte de répression ouvrière. Cent deux intellectuels espagnols professeurs universitaires, écrivains, peintres, cinéastes, etc.- se mobilisèrent contre les répressions aux Asturies et rédigèrent une lettre, reproduite par Ibérica, adressée au ministre de l'Information et du Tourisme, Fraga Iribarne ${ }^{82}$. La signature de Ridruejo était absente mais son article "Los intelectuales en el banquillo ${ }^{83}$ " apparaissait aux côtés de la lettre. Ces intellectuels tenaient à témoigner au Pouvoir leur préoccupation face à certains faits survenus dans les Asturies parmi tant d'autres, la mort de Rafael González, à la suite de mauvais traitements reçus le 3 septembre à l'Inspection de Police de Sama de Langreo. Après avoir énuméré tous les cas d'assassinats, de mauvais traitements et de sévices infligés, en particulier à des femmes, le courrier exigeait une enquête sur les activités présumées du capitaine Caro, à qui l'on imputait la responsabilité de la mort du jeune mineur Rafael González et d'autres faits, et sur tous les autres faits présumés exposés. Parmi les personnalités qui signaient cette lettre, figuraient Laín Entralgo, Aranguren, Juan Goytisolo, etc. auxquels s'ajoutaient les adhésions d'intellectuels espagnols et étrangers. Le ministre choisit de répondre à l'un des signataires, José Bergamín, et, niant les tortures mais non les sévices exercés sur les femmes, il attaquait personnellement Bergamín pour son attitude pendant la Guerre civile. Le ministre déclenchait, en outre, par l'intermédiaire d'une presse à ses ordres, une violente campagne contre les «intellectuels ». Depuis lors, une deuxième lettre, signée par 187 intellectuels, fut adressée de nouveau à Fraga et fut publiée dans le même numéro d'Ibérica. Les nouvelles signatures qui y souscrivaient se disaient solidaires de l'écrit antérieur. Cette protestation suivait la réponse de Franco, qui avait personnalisé en José Bergamín l'écrit de référence. Les signataires, maintenant les accusations qu'ils avaient déjà portées et réclamant une enquête, ajoutaient que des sanctions prises contre deux policiers permettaient de penser que les faits rapportés ne pouvaient être niés. Les intellectuels reprenaient, pour les contester, certains éléments de réponse du régime, qui ne les avaient guère convaincus, mais ils le remerciaient néanmoins d'avoir donné l'occasion de poursuivre le dialogue entamé. Aussi, cette lettre renfermait une réflexion sur la mission de l'intellectuel qui ne devait être entravée par une autorité gouvernementale, du moins dans un État libre et de droit : « Nous comprenons que la mission de l'intellectuel dans toute société libre, surtout si elle dit s'inspirer des principes chrétiens, est d'aider à éclairer la vérité et de contribuer à la formation d'une conscience publique. En conséquence, notre action a été guidée et est guidée par un concept strict de la responsabilité ; et, en accord avec ce dernier, nous jugeons qu'aucune autorité gouvernementale dans un État libre et de droit ne doive s'estimer apte à fixer les règles qui doivent régir les devoirs de l'intellectuel par 
rapport à la conscience publique, des devoirs au caractère éminemment privé et moral.»

51 Suite à ces lettres d'intellectuels précédemment citées, Fraga Iribarne et son équipe ${ }^{84}$, se préparaient à lancer une contre-offensive, qui prenait la forme d'une nouvelle campagne contre les « intellectuels ». Les menaces téléphoniques commencèrent pour les signataires les plus connus, de même que les lettres ouvertes furent publiées dans la presse, comme celle de Calvo Sotelo, qui demandait un procès pour les cent intellectuels. Cette contre-offensive devait déboucher sur un contre-manifeste signé par des intellectuels fidèles au régime mais cette dernière partie du programme ne put être réalisée en dépit de l'activité du ministre. C'est en raison de ces échecs de gestion que les médias officiels décidèrent d'ouvrir une "information judiciaire ", qui pouvait déboucher sur un procès pour "diffusion d'informations mensongères ». Furent convoqués devant le juge d'instruction Laín Entralgo, Vicente Aleixandre et José Bergamín. C'est de cet échange de correspondance et de cette campagne de presse menée contre les intellectuels que Ridruejo parla dans l'article intitulé "Los intelectuales en el banquillo " publié dans le même numéro d'Ibérica ${ }^{85}$, relayé et traduit par la revue française Preuves ${ }^{86}$. Il y exposait la campagne déclenchée par les autorités franquistes vers la fin de l'année précédente en réponse à deux lettres signées par près de deux cents intellectuels espagnols, qui demandaient au ministre de l'Information d'enquêter sur des tortures subies par des mineurs lors de la dernière grève des Asturies. Comme presque dix ans auparavant, Ridruejo prit la défense des intellectuels, interdits d'accomplir leur mission, contre lesquels était dirigée une campagne de discrédit et de diffamation qui, dès le début, dépassait le cadre du sujet proprement dit; et de la presse qui ne pouvait remplir son rôle d'information. Ridruejo dénonça le fait qu'il suffisait de " lire les divers éditoriaux, notes et lettres ouvertes publiés dans la plupart des journaux espagnols pour se rendre compte de la véritable intention de cette campagne ". L'éditorial du quotidien $A B C$, en particulier, ne pouvait être à cet égard plus clair ni plus précis. En vertu de cet acte, les signataires se trouvaient désormais incapables d'exercer leur rôle de guide de l'opinion publique ou de censeur moral de la vie sociale et politique. Ridruejo, dans cet article, identifiait le groupe des signataires aux intellectuels espagnols en général car, si ceux-ci n'y figuraient pas tous, ni n'étaient seuls à y figurer, les noms les plus représentatifs, les plus connus et appréciés du public y étaient du moins tous présents. Il s'agissait donc en réalité « d'interdire purement et simplement aux intellectuels d'assumer leurs fonctions. Fonctions nécessaires, de l'avis même du ministre ». Pour bien saisir le problème, Ridruejo relevait la nécessité d'examiner les antécédents et de se placer dans les circonstances, ce que le ministre et les journalistes, ajoutait-il, se gardaient bien de faire. Il rappela par conséquent à quels obstacles s'étaient heurtés les intellectuels espagnols pendant vingt-cinq ans, même sur le plan professionnel.

« Toute action sociale commune était alors impossible. Ils ont fini, cependant, par se regrouper et, depuis cinq ans, de fréquentes manifestations collectives de leur part ont attiré l'attention du gouvernement. Les intellectuels ont ainsi revendiqué leurs droits par le seul moyen qui fût à leur portée : en les exerçant de fait. »

Ridruejo affirmait que le gouvernement avait toujours répondu avec le mépris et que la presse officieuse avait fait parfois allusion à ces manifestations, mais sur un ton agressif. Dans ces conditions, le public avait toujours appris ce qu'il se passait par l'intermédiaire de la presse clandestine ou étrangère ce qui, ajoutait Ridruejo, était fort 
déplaisant pour le Pouvoir. Le caractère clandestin et de "conspiration » que l'on attribuait à la récente manifestation des intellectuels, et que l'on avait attribué à bien d'autres manifestations, n'était donc que la conséquence de l'attitude d'un Gouvernement qui ne voulait rien entendre et qui ne reconnaissait d'autre autorité que la sienne. Ridruejo ajoutait que le Gouvernement avait toujours ignoré ces manifestations mais qu'il avait aussi toujours ignoré les causes de ces manifestations, faisant référence aux grèves de 1962, à l'occasion desquelles les intellectuels s'étaient élevés contre le manque d'information du public espagnol. L'Église l'avait souligné à son tour et le ministre semblait en prendre la mesure, promettant de prêter attention au problème. Mais l'information demeurait toujours insuffisante et le resterait tant que la presse ne serait pas en mesure de poursuivre ses enquêtes jusqu'au bout et de les publier. Néanmoins, la liberté de la presse n'était pas tout. Une véritable information n'existerait que le jour où le Gouvernement espagnol accepterait aussi de reconnaître aux citoyens le droit de le remettre en cause. Les cent deux signataires n'avaient donc strictement fait, de l'avis de Ridruejo, que remplacer une presse indigente, un parlement inexistant et un ministre de l'Information incompétent : «Que ce ne soit pas à proprement parler le rôle des intellectuels, c'est possible, mais qui saurait reprocher au passant de porter secours à un blessé quand un médecin fait défaut?» Ridruejo dénonçait l'attitude du ministre qui consistait moins à dissimuler les abus qu'à paralyser ou discréditer un "groupe social capable par son autorité de réveiller l'opinion publique et de freiner l'arbitraire qui, depuis un quart de siècle, régissait et compromettait la vie publique de l'Espagne ». Cela était triste, de la part d'un ministre qui se disait ouvert, et n'était, selon lui, bon pour personne car,

"si les hommes d'État, soi-disant désireux de progrès, laissent par faiblesse, légèreté ou passion le champ libre aux extrémistes des deux bords, ils se condamnent eux-mêmes. Et ils se condamnent notamment à trouver leur plaisir dans l'exercice d'un pouvoir violent et que rien ne vient limiter. »

Quant à l'injonction faite aux intellectuels de renoncer à leurs devoirs, sous prétexte qu'en assurer l'exercice favoriserait l'influence communiste, Ridruejo répondait que c'était en réalité le régime qui ne faisait que l'encourager : "Que chacun fasse son examen de conscience». Ridruejo défendait cette action intellectuelle empêchée, au sein du régime, qui s'exerçait néanmoins de fait et qui dépassait peut-être les limites de ses attributions. Il en paierait le prix de sa liberté. Rentrer illégalement à Madrid constituait un autre acte de rébellion contre le régime. À l'époque du Congrès de Munich, en juin 1962, Ridruejo faisait déjà l'objet de poursuites judiciaires et n'avait donc pas obtenu de passeport. Aussi dut-il franchir clandestinement deux frontières pour se rendre dans la capitale de la Bavière. Menacé d'être déporté aux îles Canaries, s'il rentrait en Espagne après cette conférence, il était resté à Paris où il vécut pendant 22 mois en exil, muni d'une carte d'identité délivrée par les autorités françaises. N'ayant réussi à obtenir un passeport national malgré ses efforts qui furent contrecarrés sur instructions expresses de Madrid, il avait pris finalement la décision de repasser la frontière clandestinement, sous sa propre responsabilité, afin de rentrer dans son pays. La police espagnole, qui le reconnut alors qu'il était près de Bilbao dans une voiture française, le mit en état d'arrestation et le reconduisit à la frontière vers Saint-Jean-de-Luz. "Là, sans qu'aucune instruction officielle n'eût été transmise aux autorités frontalières, on le refoula sur la France », relataient les Informations pour la Liberté de la Culture ${ }^{87}$, qui ajoutaient: «En somme, un citoyen espagnol avait été expulsé de son propre pays, autrement dit banni, sur simple décision du Pouvoir. 
L'affaire était exceptionnelle». D'ailleurs, le gouvernement français, ému de ce procédé, s'était empressé de faire part de son étonnement aux autorités madrilènes. Toujours sous sa propre responsabilité, Ridruejo franchit une nouvelle fois la frontière et revint à Madrid où il regagna son domicile. Le 22 avril 1964, il écrivit au directeur général de la Sûreté pour l'informer des mauvais procédés de la police espagnole à son égard et de sa ferme intention de reprendre sa place dans la communauté nationale. Il avait écrit au ministre d'État, Louis Joxe, l'informant de sa décision de rentrer en Espagne car bien que le gouvernement espagnol lui eût refusé les conditions normales d'entrée et de voyage, il « cro(yait) que (sa) place (était) dans (son) pays » ${ }^{88}$, un courrier que son ami Hurtado transmit le même jour au ministre en personne, qu'il remerciait d'être intervenu en faveur de l'intellectuel ${ }^{89}$. Le 24 avril, Ridruejo fut arrêté et, après un long interrogatoire, il fut incarcéré à la prison de Carabanchel où il fut maintenu au secret pendant dix jours. On l'accusa de propagande illégale. Le juge, qui instruisit le procès, l'accusa de ce délit en raison de la publication de Escrito en España ; España 1963. Examen de una situación; de deux articles, l'un publié dans Bohemia Internacional en juillet 1962 dans lequel il commentait le Congrès de Munich - « Munich, un hecho »- et celui sur l'exécution de Julián Grimau, «La guerra continuada », et des déclarations réalisées dans la revue Ibérica à l'occasion de son passage par les États-Unis à la fin de l'année 1962. Ridruejo ne resta que deux semaines à la prison de Carabanchel, le juge décidant de le laisser en liberté conditionnelle car le gouvernement espagnol était soumis à d'intenses pressions diplomatiques, en particulier de la part du président français, le général De Gaulle qui, craignant de perdre son électorat à l'approche des élections, face à la possibilité d'un conflit, généré par les intellectuels, qui orientât l'électorat contre le gaullisme, œuvra avec les autorités espagnoles pour une mise en liberté immédiate de Ridruejo. En effet, dès que les dépêches d'agence eurent fait connaitre que Ridruejo avait été arrêté et qu'il allait comparaître devant un tribunal, aussitôt un mouvement de solidarité internationale s'organisa en sa faveur et de grandes manifestations s'organisèrent à Paris. Le Congrès pour la Liberté de la Culture intervint dans un télégramme de protestation, signé par Pierre Emmanuel, Denis de Rougemont et Ignazio Silone, à la suite de l'arrestation de M. Ridruejo envoyé à Antonio Iturmendi, ministre de la Justice du gouvernement espagnol, exprimant sa vive émotion devant la tournure de cette affaire et sa conviction que l'arrestation de Ridruejo aurait un profond retentissement auprès de l'opinion publique internationale :

« Apprenons que D. R. écrivain et militant européen jouissant estime et affection intellectuelle du monde libre a été arrêté stop Congrès pour la Liberté de la Culture organisation internationale écrivains et universitaire exprime son émotion et sa conviction que des poursuites contre Ridruejo ou maintien de son incarcération entraîneraient profondes répercussions opinion publique européenne Sentiments distingués. Pour le Comité exécutif, Pierre Emmanuel, Denis de Rougemont, Ignazio Silone ».

Différents comités du Congrès envoyèrent au même ministre des télégrammes analogues. L'Association italienne pour la Liberté de la Culture publia une protestation signée par une quarantaine d'intellectuels dont beaucoup étaient internationalement reconnus. Les messages de protestation des comités du Congrès ou d'organisations amies vinrent aussi bien des cercles de province en France que de pays lointains, du Liban, du Brésil et d'autres pays d'Amérique latine comme la Colombie, et même de la République de Corée. Le ministre de la Justice à Madrid reçut également des États-Unis un message signé de plusieurs personnalités. En mai 1964, apparaissait dans le 
périodique Ibérica une protestation contre la détention de Ridruejo en personne, accusé de « propagande illégale » dans des écrits publiés et des déclarations faites en dehors de l'Espagne, qui s'ajoutait à une véritable campagne de manifestations contre la détention et l'emprisonnement de Ridruejo. Les signataires signalaient qu'en vertu de l'aide économique solide que les États-Unis prêtaient à l'actuel gouvernement de l'Espagne, ils estimaient avoir le droit et le devoir de manifester publiquement leur protestation contre le Gouvernement, qui continuait de nier la liberté intellectuelle, et contre la persécution de Ridruejo pour des raisons purement idéologiques ${ }^{90}$. En France, l'Union des Écrivains pour la Vérité prit position contre le traitement infligé au poète et leader démocrate espagnol, de même que le Mouvement Fédéraliste Européen, qui organisa une campagne générale de protestation afin d'obtenir la mise en liberté provisoire de Ridruejo. De fait, il fut relaxé le 6 mai.

Cette campagne fut largement suivie en France, notamment à travers la revue Preuves ${ }^{91}$, et l'arrestation de Ridruejo fut à l'origine de bien d'autres articles dans la presse internationale, qui suivait de près depuis un certain temps la politique espagnole ${ }^{92}$. On le défendit dans de multiples articles et on réfléchit à son évolution idéologique. Pierre Emmanuel définissait Ridruejo comme

« un adversaire de grande allure pour le régime (qui), en allant se livrer aux mains de celui-ci (était) fidèle à ce même sens de l'honneur qui le poussait, lui le plus exposé et le plus vulnérable des hommes, à prendre, seul en Espagne, la défense d'un autre écrivain choisi comme bouc émissaire, José Bergamín. " ${ }^{93}$

Par ce geste - poursuivait Pierre Emmanuel- Ridruejo semble dire : «Me voici en face de vous. Il est temps pour vous de regarder l'opposition en face, de voir la réalité en face. La réalité : toute l'histoire de l'Espagne depuis trente ans et demain ». Cette affaire avait eu un écho international, et des intellectuels renommés européens et américains s'ajoutèrent à la vague de protestation, parmi eux Simone de Beauvoir, Marguerite Duras, Jean-Paul Sartre, John dos Passos, Arthur Miller, Ashley Montagu et Upton Sincler. La figure de Ridruejo prit un nouveau relief et il devenait ainsi en 1964 un symbole international de l'opposition au franquisme. Son arrestation avait eu un retentissement profond auprès de l'opinion publique internationale, qui se forgea de de ce dernier une image exemplaire, celle d'un homme qui avait changé ses convictions, qui subissait maintenant les foudres d'un régime intolérant, allant jusqu'à l'expulser de sa patrie, alors même qu'il était appelé à prendre la tête de l'opposition à ce dernier sur la voie d'un dialogue sincère et nécessaire, jetant un pont avec les vaincus de la Guerre civile.

\section{Les intellectuels unis face aux événements universitaires de 1965}

Les mois de février se suivaient et se ressemblaient, les manifestations universitaires se répétaient depuis l'année 1957, beaucoup espérant qu'il s'agît du dernier printemps de Franco, mais ces mois de février étaient inlassablement suivis de la répression policière et des procès, dont Ridruejo aussi avait de nouveau été victime car il avait recommencé à protester, comme l'affirmait El Tiempo de ${ }^{94}$. Le 24 février 1965, se réunit dans le vestibule de la Faculté de Philosophie et de Lettres de l'Université de Madrid une Assemblée Libre d'Étudiants, avec la participation des élèves de cette dernière et d'autres facultés. Ils étaient trois mille et les discussions de cette Assemblée furent 
menées par les professeurs Aranguren, Montero Díaz et García Calvo. On y traita de l'ordre du jour établi durant des réunions antérieures : réclamer la liberté syndicale, exiger un Syndicat indépendant du parti unique, demander la liberté d'expression pour l'Université, etc. À la fin des débats, on décida d'entamer une marche silencieuse du Rectorat à la Ville Universitaire. Le cortège, augmenté de deux mille étudiants avec les trois professeurs cités à sa tête, se mit en marche. Surgit immédiatement la force publique avec l'ordre de suspendre la marche et de disperser les congressistes. Les professeurs expliquèrent leur objectif pacifique, demandant cependant que l'on autorisât une commission à rendre visite au recteur. Mais la demande se conclut avec perte et fracas, des étudiants furent blessés et on dénombra trois cents détenus, parmi eux quatre professeurs, que l'on remit ensuite en liberté. Le jour suivant, une nouvelle Assemblée fut convoquée, les esprits s'échauffèrent d'autant que l'on informa les présents que les autorités avaient suspendu de leurs fonctions García Calvo, Aranguren et Montero Díaz, et qu'un étudiant avait été gravement blessé durant les répressions de la veille. L'Assemblée s'accorda pour protester contre ces violences et conclut une grève générale. Le 27 , la destitution des professeurs cités était officiellement annoncée, à laquelle s'ajoutait celle de Tierno Galván, qui appartenait à l'Université de Salamanque. Le MIT retira à José Antonio Novais - qui travaillait depuis de nombreuses années en Espagne pour Le Monde- sa carte de correspondant de presse étrangère pour un article publié sur les événements universitaires du 24 février à Madrid, qui faisait état de cent blessés, dont vingt graves et un très grave, durant la dissolution de la manifestation. Le directeur général de la Presse argumenta que la nouvelle était infondée et fausse. Cela provoqua un flot impressionnant de critiques contre le régime espagnol en général et contre le ministre de L'Information en particulier. Novais put compter sur toute l'opposition démocratique espagnole et étrangère et sur de larges secteurs du pays qui, bien qu'encore fidèles à la dictature, estimaient qu'un ministre qui combattait ses adversaires supposés par l'insulte, dépassait toutes les règles de civisme.

Le 28 février Pedro Laín Entralgo, professeur d'Histoire de la Médecine, adressa une lettre au doyen de sa Faculté, le professeur Benigno Lorenzo Velázquez, en signe de protestation sur les excès commis avec les étudiants le 24, dans laquelle il se montrait solidaire des professeurs et des étudiants concernés. Le $1^{\text {er }}$ mars, Ridruejo envoyait à son tour un courrier à l'Archevêque de Madrid, Casimiro Morcillo, pour manifester son désaccord sur la note des "Padres de Familia » parue dans $A B C$, qui faisait fi des faits réels de la marche organisée par les étudiants et du rôle qu'avaient dans ce cortège les professeurs sanctionnés. On avait construit une histoire obscure sur ces événements, dénonçait Ridruejo, signalant ses préoccupations quant à la répression exercée et au fait que les membres de cette association réclamaient dans leur note des châtiments pour les professeurs et les élèves ${ }^{95}$. Quelques jours plus tard, le 12 mars, 1161 signataires -écrivains, professionnels, artistes- adressèrent au ministre de l'Information une lettre, y joignant un document de pétition. Dans ce document, après avoir examiné la situation créée après les événements universitaires et ouvriers, les signataires sollicitaient la reconnaissance des libertés syndicales et d'association, du droit de grève, les libertés d'information et d'expression et la liberté pour ceux qui avaient été condamnés pour les faits indiqués, leur réintégration à leur poste ou la réhabilitation des étudiants sanctionnés. Cet écrit était signé, entre autres, par Ridruejo, Laín, Aranguren, Valverde, Valentín Andrés Álvarez, Julián Marías, José Antonio Maravall, Antonio Buero Vallejo, Antoni Tàpies, José María Gil-Robles, etc. 
Cette lettre montrait que les intellectuels réconciliés depuis Munich, pouvaient agir ensemble contre le régime. Ils avaient dépassé leurs clivages pour protester d'une seule voix contre la fausse information et les insultes faites à l'intelligence et ils pouvaient compter sur des organes de presse extérieure pour publier leurs articles et lettres ouvertes, qui étaient autant d'armes contre l'intolérance du régime.

C'est une nouvelle opposition qui put naître dès les premiers contacts établis lors du Congrès de Munich, dont le succès put se mesurer à l'aune des insultes proférées depuis la presse du régime. Ce Congrès n'était pourtant pas une conjuration mais il scella la réconciliation des deux Espagnes, symbolisée par la poignée de main entre Gil-Robles et Llopis. Les congressistes traîtres furent sanctionnés par le régime, mais cette sanction ne fit que renforcer les premiers liens établis, ce qui leur permit de se réunir au sein de cette nouvelle opposition en exil. À Paris, le sanctionné Ridruejo devenait l'un des opposants publics du régime, internationalement reconnu, qui pouvait maintenant donner son opinion sur la situation politique de l'Espagne au même titre que des exilés républicains, comme Prados Arrarte.

Le dialogue ouvert à Munich exigeait une continuité et, alors que l'arrivée de Fraga au Ministère n'avait rien changé -pis encore la situation était en train de s'assombrir concernant la Censure-, le dialogue se poursuivit à l'extérieur. La presse espagnole en exil, avec notamment la revue Ibérica ou encore Mañana, de même que la presse internationale, se firent l'écho de l'action intellectuelle visant à surmonter les conséquences de la Guerre civile. Il s'agissait d'éveiller les consciences et de compléter l'information fragmentaire du Gouvernement. La presse intérieure s'engagea aussi dans cette mission, à travers Cuadernos para el Diálogo, qui tenta d'encourager le dialogue entre le vainqueur catholique et l'ouvrier vaincu, une excellente conjuration face à l'état de guerre continu.

61 L'action des intellectuels dépassa néanmoins le plan strictement journalistique pour s'étendre jusqu'au terrain de la cité. Les intellectuels tenaient à revendiquer leurs droits en les exerçant de fait. C'est ce qu'avait entrepris Ridruejo en traversant illégalement la frontière pour rejoindre sa patrie. Par leurs manifestes et protestations, lors des événements ouvriers puis universitaires, les intellectuels agissaient contre un régime, qui continuait de bafouer les libertés et qui faisait mine de changer sous la pression internationale. Ils pouvaient agir ensemble, à travers leurs lettres ouvertes, manifestes et autres protestations, dépassant leurs clivages et, aidés d'intellectuels du monde entier, ils protestèrent d'une seule voix contre la fausse information et pour l'intelligence malgré les limites imposées par le régime. Leur action fut le ciment d'une Espagne nouvelle, qui devait s'intégrer dans le concert des nations démocratiques et où l'intellectuel pourrait continuer d'exercer dignement sa mission.

BIBLIOGRAPHIE 


\section{BIBLIOGRAPHIE}

ABELLÁN, José Luis, El exilio filosófico en América. Los transterrados de 1939. Madrid: Fondo de Cultura Económica, 1998.

AUBERT, Paul (dir.), Les intellectuels en Espagne de la dictature à la démocratie (1939-1986). Bulletin d'Histoire Contemporaine de l'Espagne, n50, Aix-en-Provence : PUP, 2015, p.

BENET, Josep et al. Dionisio Ridruejo, de la Falange a la oposición. Madrid, Taurus, 1976.

JULIÁ, Santos, Memoria de la guerra y del franquismo, Madrid, Taurus, 2006.

MORENTE, Francisco, Dionisio Ridruejo. Del fascismo al antifranquismo, Barcelone, Síntesis, 2006.

MUÑOZ SORO, Javier, Cuadernos para el Diálogo (1963-1976) Una historia cultural del segundo franquismo, Madrid, Marcial Pons, 2006.

RENAUDET, Isabelle, Un parlement de papier. La presse d'opposition au franquisme durant la dernière décennie de la dictature et la transition démocratique, Madrid, Casa de Velázquez, 2003.

SCHMIDT, Hans-Peter, Dionisio Ridruejo. Ein Mitglied der spanischen « Generation von 36 », Bonn, Romanisches Seminar der Universität Bonn, 1972.

TUÑÓN DE LARA, Manuel ; BIESCAS, José Antonio, «El poder y la oposición», España bajo la dictadura franquista (1939-1975). Barcelone, Labor, 1983 (2ª ed.), Barcelone, Labor, 1983, p. 344-345.

TUSELL, Javier, La oposición democrática al Franquismo, Barcelone, Planeta, 1975.

TUSELL, Javier, La dictadura de Franco. Barcelone, Altaya, 1996.

VILAR, Sergio, La oposición a la dictadura. Protagonistas de la España contemporánea. Barcelone, Ayma, 1976.

VILAR, Sergio, La naturaleza del Franquismo, Barcelone, Península, 1977.

VILAR, Sergio, Historia del antifranquismo (1939-1975), Barcelone, Plaza y Janés, 1984.

YSÀs, Père, Disidencia y subversión. La lucha del régimen franquista por su supervivencia, 1960-1975, Barcelone, Crítica, 2004.

\section{NOTES}

1. «El Congreso de Munich », Joaquín Satrústegui, Jaime Miralles, Fernando Álvarez de Miranda, 29 juin 1962, (Fonds Dionisio Ridruejo Centro de la Memoria Histórica de Salamanca MF/R 5959).

2. Ibid.

3. Francisco Morente, Dionisio Ridruejo, del fascismo al antifranquismo, Barcelone, Síntesis, 2006, p. 475.

4. Ibid.

5. Manuel Tuñón de Lara, "El poder y la oposición », in J. A. Biescas et M. Tuñón de Lara (dir.), España bajo la dictadura franquista (1939-1975), Barcelone, Labor, 1983, p. 344-345.

6. « La traición y la estupidez, aliadas en sucio conturbenio contra España », Arriba, 9 juin 1962.

7. « Texto aclamado por el Congreso del Movimiento Europeo, en Múnich, el 8 de junio de 1962 », MF/R 5970 ; Dionisio, Casi unas memorias, op.cit., p. 388.

8. «El Congreso de Munich », Joaquín Satrústegui, Jaime Miralles, Fernando Álvarez de Miranda, art. cit.

9. Francisco Morente, op. cit., p. 477. 
10. «La traición y la estupidez, aliadas en sucio contubernioD contra España », Arriba, 9 juin 1962. 11. Cf. lettre de Dionisio Ridruejo à Rodolfo Llopis, secrétaire de la Unión de Fuerzas Democráticas, Paris, 23 juillet 1962, et réponse de Rodolfo Llopis, MF/R 5957.

12. Julián Gorkin, « Mi encuentro hispano-europeísta con Dionisio Ridruejo », in J. Benet, Dionisio Ridruejo. De la Falange a la oposición, Madrid, Taurus, 1976, p. 133-144.

13. Ibid.

14. «Texto aclamado por el Congreso del Movimiento europeo, en Munich, el 8 de junio de 1962 », Casi unas memorias, op. cit., p. 388.

15. Dionisio Ridruejo, «Múnich, un hecho», Ibérica, juillet 1962 ; Dionisio, Casi unas memorias, op.cit., p. 391-393.

16. Ibid., p. 391.

17. Lettre de Dionisio Ridruejo au directeur de Combat, Paris, 21 juin 1962, MF/R 5927.

18. «El pacto de los fracasados », Pueblo, 11 juin 1962.

19. Ibid.

20. "La traición y la estupidez, aliadas en sucio contubernio contra España », Arriba, 9 juin 1962.

21. «El pacto de los fracasados », Pueblo, 11 juin 1962.

22. Cité par Hans Peter Schmidt, op. cit., 1972, p. 216.

23. Lettre de Rafael Flórez, Madrid, 15 août 1962, MF/R 5927. "

24. Lettre de José Luis Abellán, Porto Rico, 2 septembre 1961, MF/R 5927.

25. Francisco Fernández-Santos, « El exilio en París », in J. Benet, op. cit., p. 149-150.

26. Ibid.

27. Julián Gorkin, « Mi encuentro hispano-europeísta con Dionisio Ridruejo », in J. Benet, Ibid., p. 133-144.

28. Marcel Niedergang, «Un phalangiste et un exilé républicain m'ont dit : Pour Franco, depuis 23 ans, il y a deux sortes d'Espagnols : vainqueurs et vaincus », France Soir, 23 juin 1962.

29. Allusion détournée au poème de Louis Aragon «La rose et le réséda ».

30. Il existait au Mexique une presse d'opposition avec la revue littéraire Las Españas 1943-1963. Cf. étude introductive James Valender, Gabriel Rojo Leyra, Las Españas. Historia de una revista del exilio (1943-1963), El Colegio de México, México, 1999.

31. Lettre de Rafael A. León, Santo Domingo, 8 octobre 1962, MF/R 5927.

32. «El informe de Dionisio Ridruejo a la junta política de Phalange », Las Españas Revista literaria, Segunda época, n²6-28, México, D.F., juillet 1956, edición facsimilar, p. 43-45.

33. « Dionisio Ridruejo y la convivencia de los españoles », Boletín de Información n 1,15 août 1956, Mexique, p. 15-16.

34. Luis Ortega Sierra, «Los vencedores de ayer nos sentimos vencidos hoy »-Diálogo con Dionisio Ridruejo- (Ilustraciones: "Página 68 de la revista Bohemia de La Habana, correspondiente al número publicado el día 31 de marzo de 1957 », y página 69 de la revista Bohemia de La Habana, Diálogo de las Españas, Año 1, n¹, Mexico D. F., juillet 1957.

35. A(rana), J(osé) R(amón), « En torno a las declaraciones de Dionisio Ridruejo », 1, p. 28-30.

36. " Notas varias. Más sobre la muerte de Federico García Lorca : Carta de Dionisio Ridruejo ", Boletín de Información $\mathrm{n}^{\circ} 3-4$, février-mars 1957.

37. Diálogo de las Españas, n³, México D. F., juillet 1959.

38. Orientaciones de la Juventud Española, «El testimonio artístico» por Dionisio Ridruejo, Boletín de Información n8 México, janvier 1959, p. 4-6.

39. The Atlantic Monthly, Janvier 1961, Supplément à Spain today, vol 207 n¹ p. 71-134; Spain An Atlantic Supplement; Julián Marías, "The Spaniard», p. 73 ; Dionisio Ridruejo, «After Franco, What?», p. 77 ; Antonio Machado, «The Tides of reaction», p. 90 ; Gregorio Marañón, «The exiles », p. 94 ; José Luis L. Aranguren, «The future of Spanish Catholicism », p. 130.

40. Lettre de The Atlantic Monthly, Paris, 7 janvier 1961, MF/R 5926. 
41. Invitation de Ridruejo et de Gil Robles de la revue Preuves à participer à un débat public sur le thème « L'Espagne après Franco -L'Espagne et l'Europe », Paris 12 novembre 1962, MF/R 5927.

42. Lettre d'Anselmo Carretero y Jiménez à Dionisio Ridruejo, México, 19 août 1962, MF/R 5927.

43. Lettre de Dionisio Ridruejo au directeur de Combat, Paris, 21 juin 1962, MF/R 5927.

44. Jacques Ferrier, «L'Espagne, dictature usée, La vie et l'avis d'un chef de l'opposition libérale », La Tribune de Genève, 5 juin 1962, MF/R 5946.

45. Dionisio Ridruejo, Réponses à L'Express, Paris, 14 juin 1962. "Espagne. Contre la Guerre civile », MF/R 5946.

46. Lettre de Victoria Kent à Dionisio Ridruejo, 17 décembre 1962, MF/R 5927.

47. Victoria Kent à Dionisio Ridruejo, New-York, 11 novembre 1963, MF/ R 5928.

48. Manuel Jiménez Fernández, José María Gil Robles, Dionisio Ridruejo, « Algunas opiniones de la oposición ", Ibérica, vol. 8, n9, 15 septembre 1960.

49. Interview de Dionisio Ridruejo, Le Figaro, 17 mai 1962, Ibérica, vol.10, n6, 15 juin 1962.

50. Dionisio Ridruejo, «Munich, un hecho ", Ibérica, juillet 1962 ; Dionisio Ridruejo, Casi unas memorias, op.cit., p. 391-393.

51. Ibid. ; Declaraciones de Dionisio Ridruejo, Ibérica, vol. 10, n¹1, 15 novembre 1962.

52. Dionisio Ridruejo, La guerra continuada. Ecos de Munich, Barcelone, RBA, 2012, p. 157-166.

53. Dionisio Ridruejo, «L'état de guerre continu », Le Monde, MF/R 5966.

54. Julián Gorkin, «Au nom de la guerre civile », Preuves n¹48, juin 1963, p. 44-45.

55. Afiliado al escándalo, Arriba, jeudi 25 avril 1963, MF/R 5999.

56. F. Farreras, Gosar no mentir. Memòries, Barcelone, Ed. 62, 1994, p. 209 cit. par F. Morente, op. cit., p. 482.

57. F. Morente, op. cit., p. 483.

58. Dionisio Ridruejo, « Un pensamiento generacional, (A propósito de la obra de Laín Entralgo) », Cuadernos del Congreso por la libertad de la Cultura n³7, Paris, 1959-1960, juillet-août 1959, p. 27-35.

59. Julián Marías, « Una Europa abreviada en Lourmarin », Cuadernos del Congreso por la libertad de la Cultura ${ }^{\circ} 39$, novembre-décembre 1959, p. 83-86.

60. José Luis L. Aranguren, «Ética y política », Cuadernos del Congreso por la libertad de la Cultura n42, Mai-Juin 1960, p. 3-6.

61. Pedro Laín Entralgo, "El intelectual y la sociedad en que vive ", Cuadernos del Congreso por la libertad de la Cultura $\mathrm{n}^{\circ}$ 40, janvier-février 1960, p. 3-13.

62. Julián Marías, «La situación actual de la inteligencia en España », Cuadernos del Congreso por la libertad de la Cultura ${ }^{\circ} 45$, novembre-décembre 1960, p. 67-72.

63. Dionisio Ridruejo, "La vida cultural española y la problemática europeísta ", Cuadernos del Congreso por la libertad de la Cultura n41, mars-avril 1960, p. 71-75.

64. Boletín informativo del Centro de Documentación y de Estudios, París 1961-1964, n¹9, novembre 1963.

65. Dionisio Ridruejo, «Buscando claridad», Boletín informativo del Centro de Documentación y de Estudios, París $\mathrm{n}^{\circ} 19$, novembre 1963, p. 2.

66. Dionisio, Ridruejo, «La guerra continuada», Boletín informativo del Centro de Documentación y de Estudios, París n ${ }^{\circ} 16$ spécial, mai 1963, consacré à la mort de Julian Grimau.

67. Francisco Morente, op. cit., p. 490.

68. Lettre de Julián Gorkin à David, Paris, 23 février 1965, MF/R 5989.

69. «Cartel », Mañana ${ }^{\circ} 1$, janvier 1965, p. 1.

70. Anonyme, «Los de dentro y los de fuera », Mañana, tribuna democrática española ${ }^{\circ} 5$, Paris, mai 1965, p. 1.

71. Parmi les articles et lettres écrits par Ridruejo, on peut citer : Dionisio Ridruejo, «Denuncia de los violentos y elogio del temple », p. 12, 13, 23 ; « Tres cartas en torno a los sucesos », p. 16-17 (dont celle de Dionisio Ridruejo à l'Archevêque de Madrid, le $1^{\mathrm{er}}$ mars 1965); Dionisio Ridruejo, «El régimen y la transición democrática », n6, juin-juillet 1965, p. 12-14; Dionisio Ridruejo, «El 
demócrata inconsecuente (Comentarios al libro de Emilio Romero) », n¹1, janvier 1966, p. 20-23 ; Dionisio Ridruejo, « Sobre lo presente y lo futuro, nº 12, février 1966, p. 12-13; «Carta de Dionisio Ridruejo al director de $A B C$ », p. 22 ; «Carta abierta de Dionisio Ridruejo al director de $A B C$ (En torno a las resonantes declaraciones de Miguel Maura) », n²14, avril 1966 ; Dionisio Ridruejo, « La manifestación de los curas ", n¹5, mai 1966, p. 24.

72. H. P. Schmidt, op. cit., 1972, p. 221.

73. Dionisio Ridruejo, «Por qué se escribe aquí », Mañana, tribuna democrática española, $n^{\circ} 1$, Paris, janvier 1965, p. 12-13.

74. «Tres cartas en torno a los sucesos ", art. cit., Mañana, tribuna democrática española n³, Paris, mars 1965, p. 16-17 (dont celle de Dionisio Ridruejo a l'Archevêque de Madrid, le $1^{\text {er }}$ mars 1965); Dionisio Ridruejo, Casi unas memorias, op.cit., p. 407.

75. Francisco Morente, Ibid.

76. Cuadernos para el Diálogo, 31 décembre 1971.

77. «Dionisio Ridruejo a Cuadernos para el Diálogo», 31 décembre 1971. «Mesa redonda. Juicio crítico a Cuadernos para el Diálogo (Laín, Aranguren, Ruiz-Giménez, etc.)». Cuadernos para el diálogo, janvier 1972, p. 17-30.

78. Ibid.

79. Lettre de Pedro Altares à Dionisio Ridruejo, Madrid, 17 août 1965, MF/R 5929.

80. Dionisio Ridruejo, Respuestas a S. P., Cuadernos para el Diálogo, avril 1966, MF/R 5955.

81. «Ridruejo cree que Franco evolucionará», España Libre, New York, 16 novembre 1962 (Sobre una conferencia pronunciada por D. R. en San Juan de Puerto Rico), p. 4.

82. «Los intelectuales contra la represión en Asturias », Ibérica, vol. 11, n¹0, 15 octobre 1963, p. 10.

83. Dionisio Ridruejo, «Los intelectuales en el banquillo », Ibérica, vol. $11, \mathrm{n}^{\circ} 11,15$ novembre 1963, p. 6-8.

84. «Los intelectuales ante los tribunales", Madrid, 2 novembre, Ibérica, vol. $11, \mathrm{n}^{\circ} 11,15$ novembre 1963.

85. Dionisio Ridruejo, « Los intelectuales en el banquillo », art.cit.

86. Dionisio Ridruejo, «Les intellectuels espagnols au banc des accusés », Preuves, décembre 1963, p. 70.

87. "Arrestation et procès de Dionisio Ridruejo ", Informations pour la liberté de la culture (directeur de publication : Jean-Yves Bouedo), juin-août 1964.

88. Lettre de Dionisio Ridruejo à Monsieur le ministre Louis Joxe, MF/R 5928.

89. Lettre de Hurtado à Monsieur Louis Joxe, ministre secrétaire d'État, Paris, 22 avril 1964, MF/R 5928.

90. « Protesta contra la detención de Ridruejo », Ibérica, vol. 12, n5, 15 mai 1964.

91. Julián Gorkin, « Le poète D. R. emprisonné à Madrid », Preuves, Paris, 5 mai 1964.

92. Notamment, outre Le Monde; «American writers protest Spain's persecution of intellectuals», Iberian Council, 5 mai 1964; «Líder español arrestado, Dionisio Ridruejo fue sacado de su casa después de llegar clandestinamente de Francia. Encabeza una organización opositora»; «El caso Ridruejo», El Tiempo (Bogotá), 26 avril 1964 ; «25 años después, la Camisa de Ridruejo», El Tiempo (Bogotá), $1^{\mathrm{er}}$ mai 1964 ; Rodolfo Llopis, «Víctima del rencoroso régimen franquista», Le Socialiste, jeudi 11 juin 1964 ; «Prison sentence of spanish poet. Illegal propaganda charge », The Times, 25 juin 1964 ; « Arrestation et procès de Dionisio Ridruejo », Informations pour la liberté de la culture, juin-août 1964 ; « Espagne : Rejoindre la liberté est un crime », Démocratie 64, n² 232, 7 mai 1964.

93. Pierre Emmanuel, «En chemin, » Réforme, n998, 2 mai 1964, p. 10.

94. Juan Tomás de Salas, « En la España fascista: La última primavera », El Tiempo, Bogotá, 28 avril 1964.

95. Josep Benet (dir.), Dionisio Ridruejo, de la Falange a la oposición, op. cit., p. 375-377. 


\section{RÉSUMÉS}

Dans les années 60 , la scène publique changea de physionomie avec la disparition progressive des querelles spécifiquement espagnoles sur l'essence de l'Espagne entre ceux que l'on nomma les " compréhensifs » et les " exclusifs ». Les débats des années 50 changèrent de manière notable, poussés, parmi d'autres questions, par la force que prenaient les débats internationaux. L'intervention des intellectuels fut marquée par ce changement, dans un contexte de transformations sociales, dans une société différente de celle de l'après-guerre. La signature du Traité de Rome en 1957, notamment, s'ancra dans un processus ambitieux, qui allait bien au-delà de l'alliance économique, et qui avait un caractère politique, dans la mesure où l'européanisme était identifié à la démocratie et où la couverture institutionnelle pouvait être utilisée dans un sens critique envers la dictature. C'est dans ce contexte qu'une nouvelle opposition put s'organiser et dont le symbole fut le Congrès de Munich de 1962, qui permit de renouer le dialogue et de réconcilier une nouvelle opposition contre la dictature, où exil et opposition surgie de l'intérieur s'entendraient sur un vocabulaire commun face à la terreur franquiste.

En los años 60, la escena pública cambió de fisonomía con la desaparición progresiva de las querellas específicamente españolas sobre la esencia de España entre los llamados «comprensivos» y los «exclusivos». Los debates del decenio de 1950 cambiaron notablemente, impulsados, entre otras cuestiones, por la fuerza de los debates internacionales. La intervención de los intelectuales dependió de este cambio, en un contexto de transformaciones sociales, en una sociedad distinta de la de la posguerra. La firma del Tratado de Roma en 1957, en particular, se basó en un proceso ambicioso, que iba mucho más allá de la alianza económica y que tenía carácter político, en la medida en que el europeísmo estaba identificado con la democracia y donde la cobertura institucional podía ser utilizada en un sentido crítico hacia la dictadura. En este contexto se pudo organizar una nueva oposición, cuyo símbolo fue el Congreso de Munich de 1962, que permitió reanudar el diálogo y reconciliar una nueva oposición contra la dictadura, donde el exilio y la oposición surgirían desde dentro se llevarían bien en un vocabulario común frente al terror franquista.

In the 1960s, the public scene changed its face with the progressive disappearance of Spanishspecific quarrels over the essence of Spain between those called "understanding" and "exclusive". The debates of the 1950s changed significantly, driven, among other issues, by the force of international debates. The intervention of intellectuals was marked by this change, in a context of social transformations, in a society different from that of the post-war period. The signing of the Treaty of Rome in 1957, in particular, will be anchored in an ambitious process which went far beyond the economic alliance and which had a political character, to the extent that Europeanism was identified with democracy and that institutional cover could be used in a critical sense towards dictatorship. It was in this context that a new opposition could be organized, the symbol of which was the 1962 Munich Congress, which made it possible to renew dialogue and reconcile a new opposition against the dictatorship, where exile and opposition arise from within would agree on a common vocabulary in the face of Franco terror.

\section{INDEX}

Palabras claves : Antifranquismo, Intelectuales, Política exterior, España

Keywords : Antifranquism, Intellectuals, Foreign policy, Spain

Mots-clés : Antifranquisme, Intellectuels, Politique étrangère, Espagne 
AUTEUR

VANINA FILIPPI

AMU- CNRS 7303 Telemme 